\title{
FAST TRACK \\ Identification of Reggie-1 and Reggie-2 as Plasmamembrane-Associated Proteins Which Cocluster with Activated GPI-Anchored Cell Adhesion Molecules in Non-Caveolar Micropatches in Neurons
}

\author{
Dirk M. Lang, ${ }^{*}$ Silvia Lommel, ${ }^{* \star *}$ Marion Jung, Richard Ankerhold, Barbara Petrausch, \\ Ute Laessing, Marianne F. Wiechers, Helmut Plattner, Claudia A. O. Stuermer
}

Department of Biology, University of Konstanz, Universitaetsstr. 10, 78457 Konstanz, Germany

Received 16 June 1998; accepted 5 August 1998

\begin{abstract}
Neurons are believed to possess plasmalemmal microdomains and proteins analogous to the caveolae and caveolin of nonneuronal cells. Caveolae are plasmalemmal invaginations where activated glycosylphosphatidylinositol (GPI)-anchored proteins preferentially assemble and where transmembrane signaling may occur. Molecular cloning of rat reggie-1 and -2 (80\% identical to goldfish reggie proteins) shows that reggie-2 is practically identical to mouse flotillin-1. Flotillin-1 and epidermal surface antigen (ESA) (flotillin-2) are suggested to represent possible membrane proteins in caveolae. Rat reggie-1 is $\mathbf{9 9 \%}$ homologous to ESA in overlapping sequences but has a 49-amino-acid N-terminus not present in ESA. Antibodies (ABs) which recognize reggie-1 or -2 reveal that both proteins cluster at the plasmamembrane and occur in micropatches in neurons [dorsal root ganglia (DRGs), retinal ganglion, and PC-12 cells] and in nonneuronal cells. In neurons, reggie mi-
\end{abstract}

Neurons possess a complex array of cell-surface receptors for interaction with their environment and for transduction of signals that effect axon growth and

* These authors contributed equally to this study

** Present address: Institute for Genetics, University of Koeln, Weyertal 121, D-50931 Koeln, Germany

Correspondence to: C. A. O. Stuermer

Contract grant sponsor: Deutsche Forschungsgemeinschaft

Contract grant sponsor: Bundesministerium für Bildung und Forschung

Contract grant sponsor: Fonds der Chemischen Industrie cropatches occur along the axon and in lamellipodia and filopodia of growth cones, but they do not occur in caveolae. By quantitative electronmicroscopic analysis we demonstrate the absence of caveolae in (anti-caveolin negative) neurons and show anti-reggie-1 immunogoldlabeled clusters at the plasmamembrane of DRGs. When ABs against the GPI-anchored cell adhesion molecules (CAMs) F3 and Thy-1 are applied to live DRGs, the GPI-linked CAMs sequester into micropatches. Double immunofluorescence shows a colocalization of the CAMs with micropatches of anti-reggie antibodies. Thus, reggie-1 and reggie-2 identify sites where activated GPIlinked CAMs preferentially accumulate and which may represent noncaveolar micropatches (domains).

Keywords: microdomains; neurons; quantitative EM analysis; GPI-anchored CAMs; coclustering; reggie-1 and -2 
proteins such as glycosyl-phosphatidylinositol (GPI)anchored cell-surface proteins associate preferentially with them. When activated through antibody crosslinking or binding of the natural ligand, GPIanchored proteins cluster in such microdomains together with $\operatorname{src}$ family tyrosine kinases and guanosine triphosphate (GTP)-binding (G) proteins (Ying et al., 1992; Sargiacomo et al., 1993; Mayor et al., 1994) so that these structures are implicated in transmembrane signal transduction (see Lisanti et al., 1994 for review).

A morphologically distinct form of such microdomains are caveolae (see Parton, 1996, for review), which are open, flask-shaped, vesicular structures of a defined size $(0.1 \mu \mathrm{m}$ in diameter). Caveola formation seems to depend on caveolin, a $21-\mathrm{kD}$ protein with a hydrophobic portion within the caveola membrane and the $\mathrm{C}$ and $\mathrm{N}$ terminus facing the cytoplasm (Glenney and Soppet, 1989; Rothberg et al., 1992; Monier et al., 1995). Neurons and neuroblastoma cells apparently do not express caveolin and do not exhibit caveolae (Shyng et al., 1994; Gorodinsky and Harris, 1995). Yet, some investigators (Ying et al., 1992; Hermey et al., 1995) found caveolae in neuroblastoma cells. It has then been postulated that neurons may possess caveolae or functionally equivalent microdomains and proteins governing their formation and maintenance and subserving functions attributed to caveolae (Lisanti et al., 1994; Olive et al., 1995; Bickel et al., 1997; Galbiati et al., 1998).

Characteristic of the glycolipid-rich microdomains and the associated proteins is their resistance to nonionic detergent solubilization and their relative enrichment in the so-called buoyant fraction after sucrose density gradient centrifugation. This has led to the term "detergent-insoluble glycolipid-enriched domains" (DIG) (Harder and Simons, 1997).

A 47-kD protein, flotillin-1, has been identified in a nonionic detergent insoluble fraction from the brain (Bickel et al., 1997). Flotillin-1 and a protein with significant sequence homologies named "epidermal surface antigen" (ESA) or (mouse) MESA (Schroeder et al., 1994) were suggested to represent resident components of caveolae in fibroblasts and lung endothelial cells and to be associated with caveolae or caveolae-like structures in neural tissue (Bickel et al., 1997).

Mouse flotillin-1 is the homolog of a protein which we discovered independently in the goldfish central nervous system (CNS) and which we named "reggie-2" (Schulte et al., 1997) because the mRNAs of reggie- 2 and a $44 \%$ homologous protein, reggie-1, are up-regulated in fish retinal ganglion cells (RGCs) after optic nerve transection and during RGC axon regeneration. In overlapping segments, goldfish reg- gie-1 is $80 \%$ identical with ESA/MESA, which was described as a $35-\mathrm{kD}$ surface protein in keratinocytes of mice and humans (Schroeder et al., 1994).

Because our monoclonal antibody (mAB) M802 against a cell-surface protein of fish neurons immunoprecipitated reggie-1 and reggie-2, we concluded that reggie-1 and -2 are antigens of M802 (Schulte et al., 1997). We have to partially correct this view. We recently found that M802 applied to living and nonpermeabilized fish neurons recognizes a GPI-linked 48-kD cell-surface protein (Lang et al., 1998). Exposure of these cells to phosphatidylinositol-specific phospholipase C (PI-PLC) prevents M802 staining on nonpermeabilized cells. Moreover, when cells that do not express M802 antigen on their surface (fish epithelioma cells, mouse myeloma cells, and human monocytes) are subjected to fixation and permeabilization in methanol and are then exposed to M802, the antibody produces a staining pattern typical of reggie. Furthermore, in immunoblots with these cells, M802 recognizes the $47-\mathrm{kD}$ reggie proteins (Lang et al., 1998; D. M. Lang and C. A. O. Stuermer, unpublished results). This suggests that reggie-1 and -2 share an epitope with M802 antigen. This would explain why an immunoprecipitation protocol with solubilized membrane proteins and M802 leads to the purification of reggie-1 and reggie-2. A clarification of this point can be expected from cloning and sequencing of the M802 antigen; steps toward this are currently being undertaken (D. M. Lang and C. A. O. Stuermer).

Because reggie- 1 and -2 are expressed and reexpressed by fish RGCs during axon growth and regeneration, we decided to identify the reggie homologs in the rat to determine whether these two proteins are up-regulated in axon-regenerating rat RGCs. Such a comparison between fish and rat RGCs is central to an ongoing study of ours which aims to understand which proteins are essential for axon regrowth after axotomy (Jung et al., 1997). Moreover, to functionally characterize reggie- 1 and -2 and to determine whether they form microdomains where activated GPI-linked proteins cluster, the use of mammalian neurons and cell lines seemed advantageous because many more relevant proteins are known and antibodies are available to perform such experiments. When these experiments were initiated, sequence information on reggie-1 and -2 in the rat brain was not yet available except for the sequence of ESA/MESA, claimed to represent a cell-surface protein of human and mouse keratinocytes (Schroeder et al., 1994). Moreover, cRNA probes derived from the fish cDNA did not hybridize with the presumed rat reggie-1 and -2 mRNAs.

Here, we report the identification of rat reggie-1 and -2 based on polymerase chain reaction (PCR) and 
cDNA cloning procedures and primers designed from comparison of fish reggie-1 with mouse and human ESA, and fish reggie-2 with human expressed sequence tags (EST) clones. We demonstrate that rat reggie-1 and -2 mRNAs are present in rat RGCs during axon growth in the embryo and up-regulated in axon-regenerating rat RGCs.

A new $m A B$ against fish reggie-2 was generated and used in experiments, along with polyclonal antibodies (ABs) specifically recognizing either reggie- 2 in rats and fish or rat and fish reggie-1. The commercially available $\mathrm{mAB}$ anti-ESA which specifically recognizes rat and fish reggie-1 was also used. These antibodies were employed to determine the distribution of reggie- 1 and reggie- 2 in neurons and glial cells of both rats and fish and to determine whether they are associated with the plasmamembrane and perhaps with microdomains and caveolae, as suggested by Bickel et al. (1997). In light of the controversy over the existence of caveolae in neurons, we quantitatively examined rat dorsal root ganglia (DRGs), nerve growth factor (NGF)-treated and process-bearing Phaeocromacytoma (PC-12) cells, and goldfish RGCs to determine if they exhibit vesicular structures at the cell membrane similar in size and distribution to the caveolae found in astrocytes (Parton, 1996; Cameron et al., 1997). Both fast-freezing and chemical fixation methods were employed because caveolae are reported to be sensitive to fixation (Ying et al., 1992; Anderson, 1993). Mammalian cells were probed with anti-caveolin $\mathrm{ABs}$ to confirm that the presence or absence of caveolae correlates with anti-caveolin $\mathrm{AB}$ reactivity. Immunocytochemistry with antibodies against reggie- 1 and -2 results in immunoreactive micropatches along the cytoplasmic face of the cell membrane in neurons, which we find to lack caveolae and caveolin. These micropatches also occur in astrocytes, which do have caveolae and caveolin (Parton, 1996; Cameron et al., 1997). The distribution of reggie-immunoreactive micropatches in astrocytes differs from that produced by anti-caveolin AB. Moreover, reggie micropatches persist in astrocytes which lose their punctate anti-caveolin-AB pattern upon treatment with filipin (Rothberg et al., 1990, 1992). This speaks against the view (Bickel et al., 1997) that reggie-1 and -2 are associated with caveolae. When ABs against GPI-anchored cell adhesion molecules (CAMs) were applied to live neurons, the crosslinked CAMs were found to preferentially accumulate at anti-reggie-immunopositive micropatches.

Thus, our results suggest that reggie-1 and reggie- 2 are present in neurons and nonneuronal cells where they identify micropatches which are, however, distinct from caveolae.

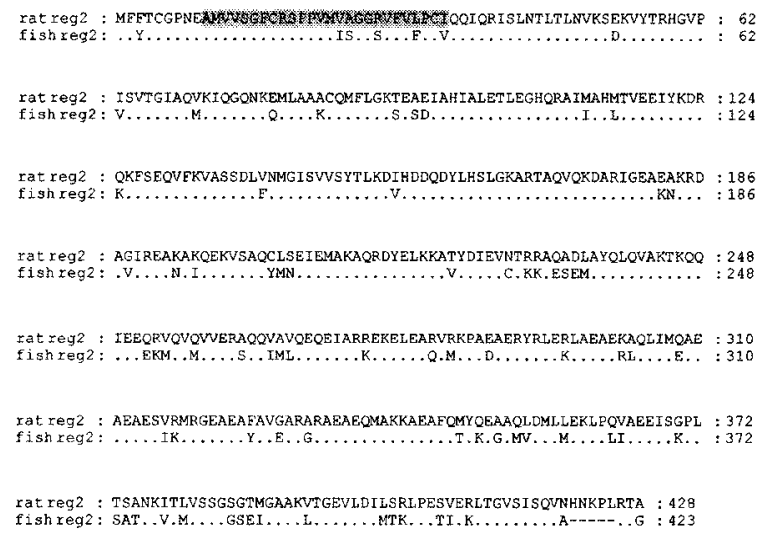

(a)

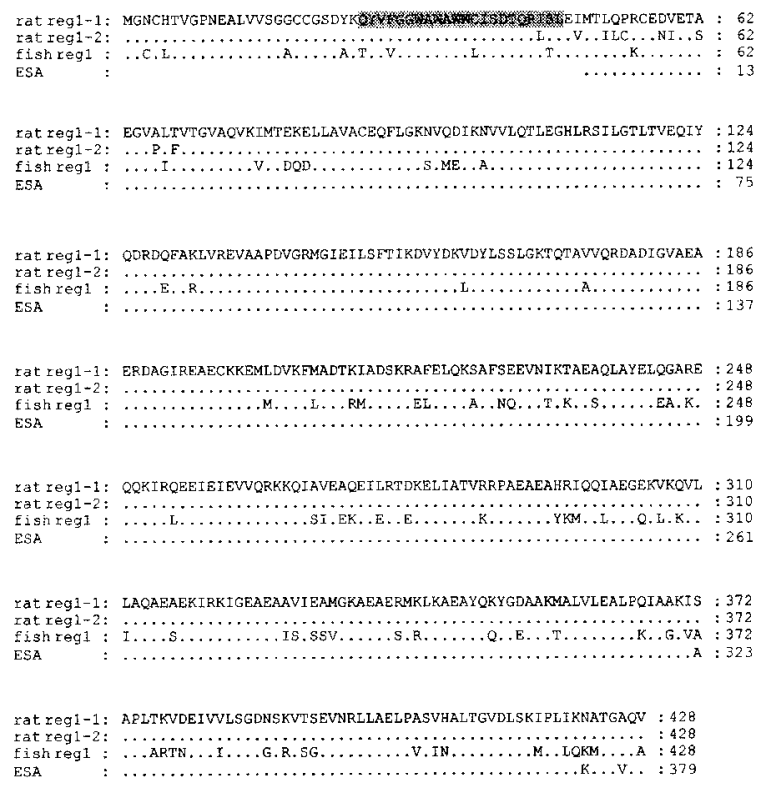

(b)

Figure 1 Sequence comparisons of rat reggie-1 and reggie-2, the goldfish homologs, and ESA. Identical amino acids are indicated by dots. Hydrophobic and putative intramembraneous amino acid sequences are shaded. (a) Rat reggie-2 (rat reg-2) sequence is $79.9 \%$ identical to fish reggie-2, and amino acid exchanges are represented. Gaps in the fish reggie-2 sequence (in comparison to that of the rat) are represented by dashes. Rat reggie-2 is practically identical to mouse flotillin-1 (Bickel et al., 1997). The rat reggie-2 sequence data are available from GenBank under accession number U60976. (b) Two rat reggie-1 sequences, rat reg 1-1 and rat reg 1-2, differ between amino acid positions $45-68$ as indicated. The overall identity between rat and fish reggie-1 is $79.9 \%$ and amino acid exchanges are represented. ESA is $99 \%$ identical with rat reg 1-1 in overlapping sequences, but the published ESA sequence starts at the methionine corresponding to amino acid position 50 of rat and goldfish reggie-1. The sequence data are available from GenBank under accession numbers AF 023302 (rat reggie 1-1) and AF 023303 (rat reggie 1-2). 


\section{MATERIALS AND METHODS}

\section{Cloning of Partial Rat Reggie-1 and Reggie-2 cDNAs}

Degenerate sense and antisense primers were designed for PCR on the basis of multiple sequence alignments of goldfish reggie-1 (Schulte et al., 1997), ESA, and MESA cDNAs (Schroeder et al., 1994), and of goldfish reggie-2 (Schulte et al., 1997) and human EST clones (HO3390, H14248, and H30476), respectively. The template for PCR was oligo(dT)-primed first-strand cDNA reverse-transcribed from $2 \mu \mathrm{g}$ poly $(\mathrm{A})^{+}$RNA using Superscript II reverse transcriptase (Gibco BRL Life Technologies, Eggenstein, Germany). PCR was carried out for 33 cycles at annealing temperatures of $58-65^{\circ} \mathrm{C}$. For reggie-1, the primer pairs S3 [5'-GC(CT) TGT GA(AG) CAG TT(CT) CTG GG-3'] and A5 [5'-CAG CAA TCT (GT)GG GCA G(GT)G C-3'] yielded a single fragment of 846 bp (as predicted based on the goldfish reggie-1 cDNA sequence) with templates of rat brain and skin of all ages analyzed. For reggie-2, a 736-bp product was amplified with all templates using the primer pair S1 [5'-GCC CAC ATT GCC (CT)TG GA(AG) AC-3'] and A4 [5'GCC TTC TT(GC) GCC ATC TGC TC$3^{\prime}$ ]. The PCR products were recovered and subcloned into the pCRScript vector according to the manufacturer's instructions (Stratagene, Heidelberg, Germany). Resulting clones from different templates were sequenced and found to represent partial rat reggie-1 and reggie-2 cDNAs.

Sequencing was carried out on both strands by the dideoxy chain termination method (Sanger et al., 1977) using the Deaza T7 sequencing kit (Pharmacia Biotech, Freiburg, Germany) with internal labeling with ${ }^{35} \mathrm{~S}$ dATP (ICN Biomedicals, Eschwege, Germany). Computer-based sequence analyses were performed employing the Wisconsin Sequence Analysis Package (Version 8; Genetics Computer Group, Madison, WI).

\section{Isolation of Full-Length Rat Reggie-1 and -2 cDNAs}

Digoxigenin (DIG)-labeled cDNA probes corresponding to the 846-bp PCR product of rat reggie-1 and the 736-bp PCR product of rat reggie- 2 were generated by random priming with the DIG High Prime kit (Boehringer Mannheim). The probes were used to screen a lambda-Uni-Zap XR rat brain cDNA library from the brains of 14- to 16-day-old male and female SpragueDawley rats (Stratagene). Hybridization was carried out in Quickhyb at $68^{\circ} \mathrm{C}$ as outlined by the manufacturer (Stratagene) and filters were washed at the same temperature with a final wash in $0.1 \times \mathrm{SSC}$ and $0.1 \%$ sodium dodecyl sulfate (SDS) followed by colorimetric detection (Boehringer Mannheim, Mannheim, Germany). For rat reggie-2, two identical full-length cDNA clones were obtained from the library screen.

Since screening of $>1 \times 10^{6}$ pfu yielded 12 partial but no full-length rat reggie-1 cDNAs, 5' RACE PCR was performed on rat brain first-strand CDNA with the 5'-AmpliFinder ${ }^{\mathrm{TM}}$ RACE kit (Clontech Laboratories, Palo Alto, CA) with nested gene-specific antisense primers A5, A12 [5'-TGG TGT CTG CCA TGA ACT TC-3'] and A1 [5'-CCT TCT CCG TCA TGA TCT TC- $\left.3^{\prime}\right]$. Resulting clones were analyzed and two clones (rat reggie $1-2 ; 1-2$ ) covering the $\mathrm{N}$ terminus predicted by comparison with goldfish reggie-1 (Schulte et al., 1997) were found. Their sequence is identical except for several exchanges between amino acid positions 45-68 [see Fig. 2(b)]. These clones were found in several independent experiments, excluding the possibility that the observed amino acid exchanges are a PCR artifact.

Full-length cDNA clones for rat reggie 1-1 and rat reggie 1-2 were generated by restriction digestion with HindIII (Boehringer Mannheim) followed by ligation of the 5' RACE PCR clones and an overlapping partial clone from the library screen. The rat reggie 1-1 and rat reggie 1-2 cDNA sequences can be found in the GenBank under the accession numbers AF023302 (rat reggie 1-1) and AF023303 (rat reggie $1-2)$. The rat reggie-2 cDNA can be found under accession number U60976.

\section{In Vitro Transcription/Translation of Rat Reggie cDNAs}

In vitro translation of radiolabeled rat reggie polypeptides was performed with the $\mathrm{TNT}^{\mathrm{R}}$ Coupled Reticulocyte Lysate system using the T3 RNA polymerase and $\left[{ }^{35} \mathrm{~S}\right]$ methionine according to the manufacturer's instructions (Promega, Mannheim, Germany). The synthesized polypeptides were size separated under reducing conditions on minigels (Pharmacia Biotech). Either gels were fixed, dried, and exposed to autoradiographic film (Eastman Kodak XAR5, Rochester, NY) or the polypeptides were immunoblotted as described below.

\section{RNA Isolation and Analysis}

Total RNA was extracted from embryonic days (E) 16 and 19, postnatal days (P) 0,3, and 9, and adult rat brain and from rat skin (E19) by the RNAzol-B ${ }^{\mathrm{TM}}$ method (WAK Chemie, Bad Soden, Germany). Poly(A) ${ }^{+}$RNA of total cellular RNA was isolated using oligo(dT)-Dynabeads (Dynal, Hamburg, Germany). Then, $0.5 \mu \mathrm{g}$ of $\operatorname{poly}(\mathrm{A})^{+}$RNA was size 

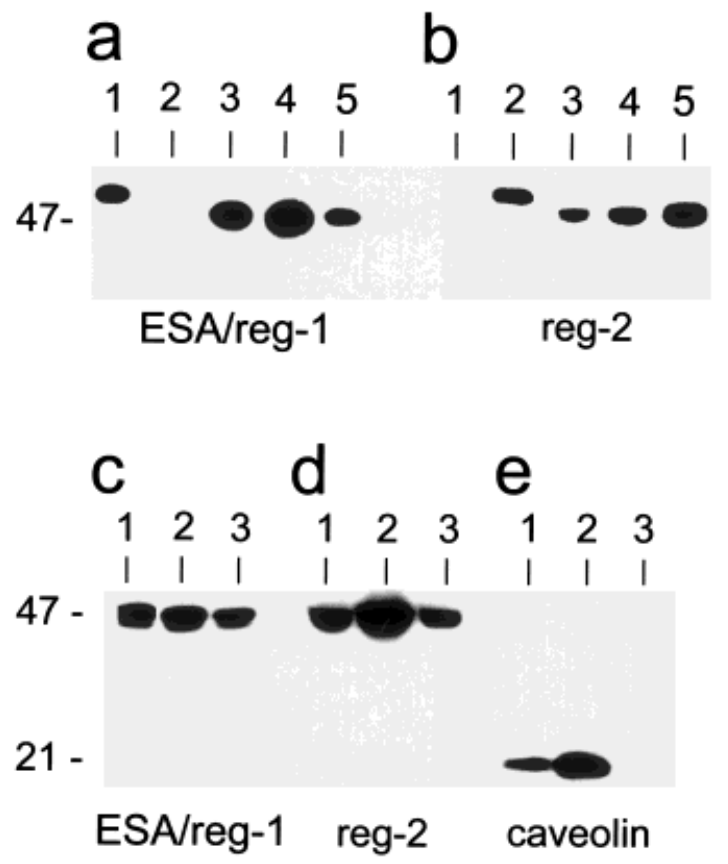

Figure 2 Immunoblot analysis with antibodies against reggie-1 and -2 and recombinant proteins and tissue homogenates. (a) Monoclonal antibody anti-ESA/reggie-1 recognizes recombinant reggie-1 (lane 1) but not reggie-2 (lane 2 ). In the goldfish brain (lane 3), rat brain (lane 4) and rat skin (lane 5), mAB anti-ESA/reggie-1 detects the 47-kD reggie-1 protein. (b) Polyclonal anti-reggie-2 ABs recognize recombinant reggie-2 (lane 2) but not reggie-1 (lane 1) and detect $47-\mathrm{kD}$ reggie-1 protein in goldfish brain (lane 3), rat brain (lane 4), and rat skin (lane 5). (c) mAB anti-ESA/ reggie-1 detects $47-\mathrm{kD}$ reggie-1 in rat oligodendrocytes (lane 1), rat astrocytes (lane 2), and PC-12 cells (lane 3). (d) Polyclonal anti-reggie-2 $\mathrm{ABs}$ recognize $47-\mathrm{kD}$ reggie- 2 in rat oligodendrocytes (lane 1) and astrocytes (lane 2) as well as in PC-12 cells (lane 3 ). (e) $\mathrm{mAB}$ anti-caveolin reveals $21-\mathrm{kD}$ caveolin in rat oligodendrocytes (lane 1) and astrocytes (lane 2) but not in PC-12 cells (lane 3 ).

separated on a denaturing formaldehyde-agarose gel, transferred to Hybond-N+ nylon membrane (Amersham Buchler, Braunschweig, Germany) (Sambrook et al., 1989) and hybridized with either $\left[{ }^{32}\right.$ P]UTP(Amersham Buchler) or digoxigenin-labeled (DIG RNA labeling kit; Boehringer Mannheim) antisense riboprobes generated as described below. Membranes were also probed with a DIG-labeled 0.2-kb riboprobe complementary to rat glyceraldehyde-3-phosphate dehydrogenase (GAPDH) for a comparison of the relative amounts of RNA loaded, and exposed to autoradiographic film.

\section{Generation of Riboprobes}

Riboprobes for Northern blotting and in situ hybridization were generated using the plasmids pBluescript
II SK(-) containing a 2.7-kb insert of rat reggie-1 and pCR-Script SK(+) containing a $0.85-\mathrm{kb}$ insert of rat reggie-1 or a $0.74-\mathrm{kb}$ insert of rat reggie-2. The plasmids were linearized with the appropriate restriction enzymes, treated with proteinase $\mathrm{K}$ (Boehringer Mannheim), extracted with phenol/chloroform, precipitated and labeled by in vitro transcription with the DIG-RNA or fluorescein-RNA labeling kit (Boehringer Mannheim) using T3 or T7 RNA polymerases. The 2.7-kb riboprobe of rat reggie-1 was reduced to a mean size of $0.2 \mathrm{~kb}$ by limited alkaline hydrolysis according to Wilkinson (1992).

\section{In Situ Hybridization}

Unilateral optic nerve crush and transplantation of a peripheral nerve graft in adult rats which were anesthetized by an intraperitoneal injection of Kemint (Alvetra, Neumuenster, Germany) and Rompun (Bayer, Leverkusen, Germany) were done as described (Jung et al., 1997) and in compliance with animal welfare legislation. In situ hybridization experiments with reggie-1- and reggie-2-specific cRNA probes on rat CNS tissue were performed as reported earlier (Jung et al., 1997). In situ hybridization with rat reggie-1 and -2 riboprobes on fixed cells (4\% PFA) was performed according to Amur-Umarjee et al. (1993) with minor modifications. In all in situ hybridization experiments, controls treated with sense riboprobes were blank.

\section{Cell Culture}

PC-12 cells (kindly provided by M. Schwab, Zurich) were grown on a polylysine/collagen substrate in DME with 2\% FCS and $100 \mathrm{ng} / \mathrm{mL}$ NGF (Sigma) for at least 7 days. N2a neuroblastoma cells [European Collection of Animal Cell Cultures (ECACC), Salisbury, UK] were cultured in DME with $10 \%$ FCS. The carp epithelioma cell line EPC (ECACC) was maintained at $20^{\circ} \mathrm{C}$ in $\mathrm{L} 15$ containing $15 \%$ FCS.

Astrocytes or oligodendrocytes were prepared from P1-3 rat brains as described in Lang et al. (1996) modified after McCarthy and DeVellis (1980). Dorsal root ganglion (DRG) neurons from P1-P3 rats were obtained by mechanical trituration of tissue fragments and separation of tissue aggregates from single cells as described (Lang et al., 1996). Cells were taken up in modified L15 medium (Mains and Patterson, 1973) with 5\% FCS and $100 \mathrm{ng} / \mathrm{mL}$ NGF (Sigma) and grown overnight $\left(\approx 10^{4}\right.$ cells $\left./ \mathrm{cm}^{2}\right)$. These cultures typically contained $<5 \%$ nonneuronal cells. For electron microscopy, rat astrocytes, PC-12 cells, and DRG neurons were plated on polylysine-coated Thermanox cell culture plastic discs (Science Services, Munich, 
Germany) to which collagen (Sigma, for PC-12 cells) or laminin (Boehringer Mannheim, for DRG neurons) was added. For immunohistochemistry and light microscopic analysis, cells were grown on glass coverslips coated with the same substrates.

Goldfish retina explants (300 $\mu \mathrm{m}$ wide) from fish which had received a conditioning nerve transection 14 days prior to use (Vielmetter et al., 1991) were placed on polylysine/laminin-coated glass coverslips or (for EM analysis) on coated Petriperm dishes and Thermanox discs, respectively. Retinal explants were cultured for at least 2 days at $27^{\circ} \mathrm{C}$ in $\mathrm{F} 12$ medium with $10 \%$ FCS and $0.4 \%$ methyl cellulose (Sigma).

\section{Production of Anti-Reggie-2 mAB}

Recombinant goldfish reggie-2 protein was isolated from transformed Escherichia coli (Schulte et al., 1997) and used to immunize a female 6-week-old $\mathrm{balb} / \mathrm{c}$ mouse according to standard protocols (Vielmetter et al., 1991). Hybridoma cells were produced under standard culture conditions. In immunostaining and blotting experiments, a purified $\mathrm{IgG}$ fraction of polyclonal anti-reggie-2 was employed.

\section{Gel Electrophoresis and Immunoblotting}

For SDS-PAGE and immunoblots (Sambrook et al., 1989), proteins were separated on $10 \%$ or $12 \%$ minigels under reducing conditions. Following gel electrophoresis, proteins were transferred to Hybond-C Super nitrocellulose membranes (Amersham Buchler) in a tank blot apparatus. The membranes were airdried, blocked in PBS containing 0.05\% Tween-20 and $3 \%$ nonfat dried milk or $3 \%$ BSA [ $1 \mathrm{~h}$ at room temperature (RT)], and incubated with the relevant antibodies defined below in blocking solution for $2 \mathrm{~h}$ at RT or overnight at $4^{\circ} \mathrm{C}$. Following four washes in PBS/0.05\% Tween-20, the blots were incubated with horseradish peroxidase(HRP)-conjugated goat-antirabbit or goat-anti-mouse antibodies in blocking solution for $2 \mathrm{~h}$ at RT, and after extensive washing, developed using the enhanced chemoluminescence (ECL) detection kit (Amersham Buchler) and ECL hyperfilm (Amersham Buchler).

\section{Preparation of Detergent-Resistant Membrane Fractions}

Detergent resistant membrane fractions of neonatal rat brain and PC-12 cells were prepared as described by Henke et al. (1996). Briefly, membrane fractions were obtained by sucrose density gradient centrifugation and extracted in the presence of $1 \%$ Triton-X-100 on ice. Following addition of sucrose to a final concen- tration of $25 \%$, the extracts were layed between $40 \%$ and $10 \%$ sucrose and again subjected to density gradient centrifugation. The soluble fraction contained in the $25 \%$ sucrose band as well as the Triton-X-100 insoluble fraction at the $10 / 25 \%$ sucrose interface were collected. Prior to Western blotting, the fractions were separated on $12 \%$ minigels with $10 \mu \mathrm{g}$ protein/ lane.

\section{Immunohistochemistry}

Primary antibodies were $\mathrm{mAB}$ and polyclonal anticaveolin antibodies (Transduction Laboratories, Lexington, KY), mAB SMI-31 against phosphoneurofilaments (Sternberger Monoclonals, Baltimore, MD), mAB anti-ESA (Transduction Laboratories) recognizing rat and goldfish reggie-1 (and therefore named ESA/reggie-1 here); $\mathrm{mAB}$ anti-goldfish reggie-2, mAB anti-Thy-1 (BioTrend, Koeln, Germany), as well as polyclonal antibodies (ABs) anti-L1 (kindly provided by F. Rathjen, Berlin), anti-F3 (kindly provided by G. Gennarini, Bari), anti-goldfish reggie-1 and -2 (Schulte et al., 1997), and anti-c-src (Upstate Biotechnology, Lake Placid, NY).

Antibodies against the GPI-anchored CAMs (F3 and Thy-1) and L1 were applied to live cells at either $4^{\circ} \mathrm{C}$ for $1 \mathrm{~h}$ or $37^{\circ} \mathrm{C}$ for $45 \mathrm{~min}$. Alternatively, cells were fixed in $4 \%$ PFA ( 5 min at RT) prior to application of the antibodies. For double staining with anti-caveolin or anti-reggie-1, $-2 \mathrm{ABs}$, cells were permeabilized with methanol $\left(5 \mathrm{~min}\right.$ at $\left.-20^{\circ} \mathrm{C}\right)$ or $0.1 \%$ Triton-X-100 following PFA fixation. After at least three washes in PBS, nonspecific binding sites were blocked with $1 \%$ BSA in PBS $\left(30\right.$ min at $\left.37^{\circ} \mathrm{C}\right)$. The cells were then incubated with anti-caveolin or antireggie $\mathrm{ABs}$ in blocking solution $\left(2 \mathrm{~h}\right.$ at $\left.37^{\circ} \mathrm{C}\right)$, washed with PBS, and incubated with the appropriate secondary $\mathrm{ABs}\left(1 \mathrm{~h}\right.$ at $\left.37^{\circ} \mathrm{C}\right)$ : either donkey-anti-rabbit-(or anti-mouse) CY-3 (Dianova), donkey-anti-rabbit (or anti-mouse) ALEXA 546 or goat-anti-rabbit (or antimouse) ALEXA 488 (Molecular Probes, Eugene, OR). The cultures were rinsed in PBS and coverslipped in Mowiol containing $n$-propylgallate as an antifading agent.

Filipin (Sigma), a polyene drug known to bind cholesterol, disrupt caveolae, and induce a redistribution of caveolin and anti-caveolin immunopositive puncta (Rothberg et al., 1990, 1992) was dissolved in DMSO $(5 \mathrm{mg} / \mathrm{mL})$ and brought to a final concentration of $5 \mu \mathrm{g} / \mathrm{mL}$ in DME. Live rat astrocytes were exposed to filipin $\left(1 \mathrm{~h} \mathrm{at} 37^{\circ} \mathrm{C}\right)$, and controls to DMSO in DME without filipin. After brief washes in DME, the cells were fixed in 4\% PFA in PBS (5 min at RT), permeabilized in methanol $\left(5 \mathrm{~min}\right.$ at $\left.-20^{\circ} \mathrm{C}\right)$, exposed to anti-caveolin and anti-ESA/reggie-1 ABs, 
washed extensively, and incubated with secondary antibodies. Stained cells were analyzed and photographed with a fluorescence microscope (Axiophot, Zeiss, Germany) equipped with a $\times 100$ oil-immersion lens and appropriate filter sets. Negatives were scanned and processed using the Photoshop software (Adobe, San Jose, CA).

Quantification of immunofluorescent micropatches and evaluation of coclustering in double-labeling experiments was performed as described (Mayor et al., 1994). In brief, photomicrographs of rat DRG growth cones were scanned at high resolution and red and green immunofluorescence images were superimposed. The numbers of red, green, and yellow (i.e., coincident) patches in 10 randomly selected fields of $9 \mu \mathrm{m}^{2}$ each per growth cone were counted and averaged in at least three growth cones per experiment. The extent of random colocalization was estimated by shifting one of the superimposed images by $5 \mu \mathrm{m}$ along the $x$ and $y$ axis (Mayor et al., 1994) and performing counts as above.

\section{Preparation for Electronmicroscopy (EM)}

Cells grown on Thermanox disks were subjected to sandwich freezing according to Pscheid et al. (1981), i.e., by shooting a one-sided jet of propane of close to $-150^{\circ} \mathrm{C}$ (controlled by thermocouple) onto the covering copper disk. Previous simulations with $30-\mu \mathrm{m}$ thermocouples and oscillographic evaluation showed cooling rates of $\sim 4 \times 10^{4 \circ} \mathrm{C}^{\circ} \mathrm{s}^{-1}$, in a temperature range of +22 to $-80^{\circ} \mathrm{C}$ (Plattner and Bachmann, 1982; Knoll et al., 1991). (a) Cryofixation was combined with freeze substitution in $1 \% \mathrm{w} / \mathrm{v} \mathrm{OsO}_{4}+3 \%$ $\mathrm{v} / \mathrm{v}$ glutaraldehyde $+0.5 \% \mathrm{w} / \mathrm{v}$ uranylacetate in methanol at $-80^{\circ} \mathrm{C}$ (Knoll et al., 1991). (b) Aliquots were immersed in $2 \% \mathrm{w} / \mathrm{v} \mathrm{OsO}_{4}$ solution at $0^{\circ} \mathrm{C}$, possibly the fastest chemical inactivation of cells (Plattner and Zingsheim, 1983). (c) Another fixation was in $4 \%$ PFA and $0.1 \%$ glutaraldehyde $\left(1 \mathrm{~h}\right.$ at $\left.0^{\circ} \mathrm{C}\right)$ in $0.1 M$ Pipes buffer (pH 7.2), or (d) in $3 \%$ PFA, 3 $\mathrm{m} M$ picric acid, $4 \mathrm{mM} \mathrm{KCl}$ and $2 \mathrm{mM} \mathrm{MgCl}_{2}(1 \mathrm{~h}$ at $0^{\circ} \mathrm{C}$ ) in the same buffer. After ethanol dehydration with decreasing temperature samples were embedded in the hydrophilic methacrylate, Unicryl (British BioCell, London, UK) at $-30^{\circ} \mathrm{C}$ (progressive lowering of the temperature method; PLT). Unicryl polymerization was induced by ultraviolet (UV) light $(15 \mathrm{~W})$ at $-30^{\circ} \mathrm{C}$ for $24 \mathrm{~h}$. Samples treated by methods (c) and (d) were used for immuno-EM localization of reggie-1. Methods (a) and (c) were followed by routine embedding in Spurr's resin and polymerization at $70^{\circ} \mathrm{C}$, production of sections of silver interference color, and routine staining with uranyl acetate and lead citrate.

\section{Ultrastructural Analysis}

A Zeiss EM10 was operated at nominally 20,000 times magnification. According to calibration with latex beads $(0.822 \pm 0.0034 \mu \mathrm{m}$; Serva, Heidelberg, Germany) real magnification was 17,660 times. All measurements were corrected accordingly. Section thickness was registered, on samples from all experiments, on occasional folds. Micrographs were taken randomly, irrespective of the number of structures to be analyzed and of the size of a cell region (including cell bodies and even small cell extensions) unless indicated otherwise. Vesicles of any size, directly attached to or fused with the cell membrane, were evaluated on micrographs enlarged 2.2 times, using a calibrated magnifying lens. Their width and height, parallel or vertical to the cell membrane, respectively, was registered. As a reference, cell membrane length was determined by the hit point method using a square grid of a lattice constant of $10 \mathrm{~mm}$. Cell regions with the cell membrane not vertically cut were excluded. For methodical details on morphometry, see Plattner et al. (1997).

Since "small vesicles" and "caveolae" candidates have a medium width of 55 and $80-90 \mathrm{~nm}$ (see Table $2)$, respectively, this is comparable to section thickness $[67.1 \pm 17.2 \mathrm{~nm}$ standard deviation (S.D.); $n$ $=13]$. Therefore, the number of organelles per square micrometer would be overestimated by a factor of $\sim 1.5$ (Holmes effect). This was corrected accordingly (see Table 3).

\section{Statistical Evaluation of Ultrastructural Data}

The size distribution of cell membrane-associated vesicles/caveolae was evaluated as follows. From the $a$ and $b$ axis (height and width, respectively), the area of these elliptic structures was calculated and plotted in unit bins. Since a bimodal distribution was clearly recognized in cells with established caveolae (astrocytes), vesicles were treated as two separate populations. Their average size and size limit was determined (see Fig. 9). Structures counted were referred to the area of cell membrane analyzed (profile length $\times$ section thickness, corrected by a factor of 1.5 for Holmes; see above) to determine packing density (organelles per square micrometer of cell membrane). 


\section{EM Immunocytochemistry}

Ultrathin Unicryl sections were washed with BSA-C (BioTrend) in PBS (with Tween-20 added), followed by incubation with $\mathrm{mAB}$ anti-ESA/reggie-1 diluted 1:1000, and then by goat-anti-mouse $A B$ coupled to 5-nm gold particles $\left(\mathrm{Au}_{5}\right)$ diluted 1:10 (Polysciences, Warrington, PA). Sections were stained for $3 \mathrm{~min}$ with $3 \%$ aqueous uranyl acetate and analyzed in an LEO/Zeiss electron microscope type EM912 Omega operated at $80 \mathrm{kV}$, with a $30-\mu \mathrm{m}$ objective aperture at zero energy loss.

\section{RESULTS}

\section{Molecular Cloning of Rat Reggie-1 and -2}

To determine whether reggie- 1 and reggie- 2 are expressed in neurons of the rat nervous system during axon growth and whether their distribution coincides with that of microdomains, we first identified the rat-reggie homologs by cDNA cloning, studied the expression of rat reggie-1 and -2 mRNAs by in situ hybridization, and localized the proteins by immunocytochemistry.

An RT-PCR cloning strategy with degenerate oligonucleotide primers designed on the basis of sequence comparisons of goldfish reggie-1 with ESA/ MESA, and goldfish reggie-2 (Schulte et al., 1997; Schroeder et al., 1994) with human EST clones was employed to isolate partial rat reggie-1 and rat reggie-2 cDNAs. The resulting PCR fragments were used to screen a cDNA library of 14- to 16-day-old rat brains.

The 1.7-kb-long rat reggie-2 clone contains an open reading frame that encodes a polypeptide of 428 amino acids and exhibits an overall amino acid identity of $79.9 \%$ with goldfish reggie-2 [Fig. 1(a)]. A protein named flotillin-1, which was isolated from a fraction of proteins from murine 3T3-L1 adipocytes and which is characterized by its nonionic detergent insolubility (Bickel et al., 1997), is identical to rat reggie-2 except for one aminoacid substitution at position 327 (valin in reggie-2 corresponds to isoleucine in flotillin-1).

Since rat reggie- $1 \mathrm{cDNAs}$ were incomplete at their $5^{\prime}$ ends compared to goldfish reggie-1, the RACEPCR technique was employed as described in Materials and Methods to obtain the $\mathrm{N}$ terminus. Two rat-reggie-1 5'-RACE-PCR fragments were obtained containing the complete $\mathrm{N}$ terminus by comparison with the goldfish reggie-1 sequence. Full-length clones were generated by fusing the $5^{\prime}$-RACE-PCR fragments and an overlapping partial clone from the library screen.

Both full-length rat reggie-1 cDNAs (rat reggie 1-1 and 1-2) encode polypeptides of 428 amino acids [Fig. 1(b)] with a predicted molecular weight of 47 $\mathrm{kD}$ which corresponds to the in vitro translation products. As indicated in Figure 1, rat reggie 1-1 and 1-2 show amino acid exchanges in the sequence segment position 45-68 and we suspect they represent splice variants. Polyclonal antibodies raised against recombinant goldfish reggie-1 recognized the in vitro translation products and revealed a protein at $47 \mathrm{kD}$ in immunoblot analyses with homogenates of rat tissue. The same $47-\mathrm{kD}$ band was obtained in these immunoblots when the commercially available mAB against ESA was employed (Fig. 2).

Database comparisons show that rat reggie 1-1 is $100 \%$ identical to MESA in corresponding sequence segments (amino acids 50-428) [Fig. 1(b)], but rat reggie 1-2 differs from rat reggie 1-1 over the region we believe to be alternatively spliced, and is therefore only $98 \%$ identical. The existence of human, murine, and Drosophila EST clones which cover the sequence segment missing in ESA/MESA indicates that the first 49 amino acids of goldfish and rat reggie- 1 represent the $\mathrm{N}$ terminus.

Northern blot analysis shows that reggie-1 and reggie-2 mRNAs are expressed in rat brain during embryogenesis [E16 and E19] and postnatal stages [P3 and P9], and in the adult (Fig. 3). Both mRNAs are also expressed in the skin [E19] (Fig. 3), as was reported for MESA/ESA in mice and humans (Schroeder et al., 1994), and for reggie-1 and -2 in fish (Schulte et al., 1997). Concerning reggie-2 mRNA expression in the rat brain, our findings are consistent with results by Bickel et al. (1997) showing the presence of flotillin-1 mRNA in the mouse brain.

\section{Sequence Analysis}

In comparison with fish reggie- 1 and -2 , rat reggie- 1 and -2 show a remarkably high degree of sequence identity on the amino acid level, being $79.9 \%$ both for reggie-1 and for reggie-2 (Fig. 1). Hydrophobicity plots and computer-assisted motif analyses suggest that reggie- 1 is predominantly hydrophilic and has one hydrophobic region [Fig. 1(b)] suggestive of a trans- or intramembrane domain. The sequence including the glycine at position 2 complies with a potential N-myristoylation site. Like flotillin-1 (Bickel et al., 1997), reggie-2 has one hydrophobic region (position 10-35) which may represent an integral or membrane-spanning domain [Fig. 1(a)] and a short hydrophobic region (position 140-150) which is less likely to span the membrane. That both reggie-1 and -2 are cell membrane-bound and of largely cytoplasmic 


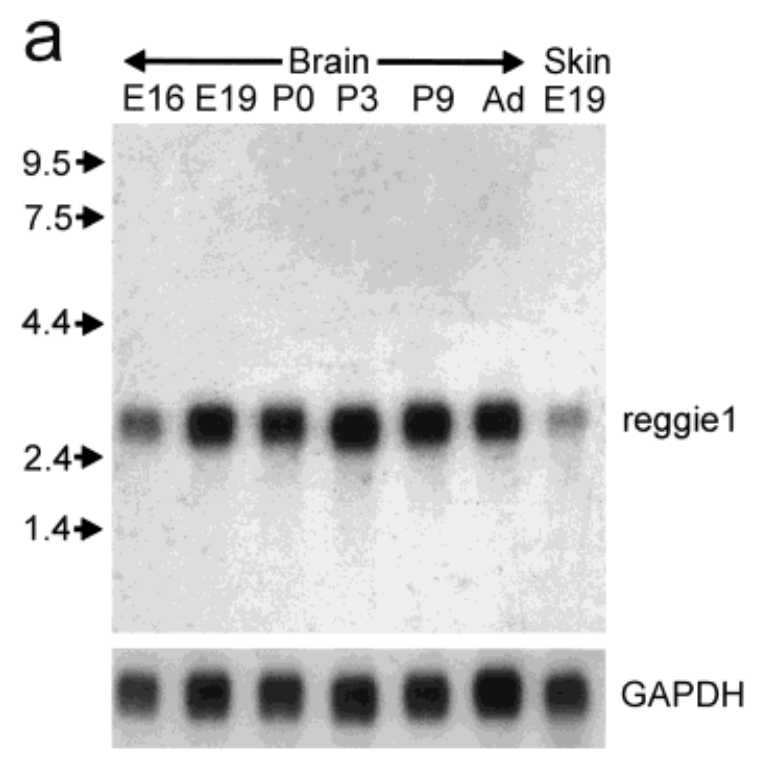

and flotillin-1 (Schroeder et al., 1994; Bickel et al., 1997) and whose relevance is unknown.

\section{Expression of Reggie-1 and Reggie-2 mRNAs and Protein in the Rat CNS and Neurons}

In situ hybridization experiments were performed to determine the regional and cellular distribution of reggie-1 and reggie- 2 mRNAs in the rat brain (including the retina), in CNS-derived glial cells (astrocytes and oligodendrocytes), in rat DRG neurons, in NGFstimulated PC-12 cells and neuroblastoma cells, and in many other neurons of the CNS (not shown).

All regions of the rat brain, the retina, and all cultured cells exhibited in situ hybridization signals with cRNA probes specific to both reggie-1 and reggie-2, but only relevant examples will be considered here.

The RGC layer of the developing retina displays in situ hybridization signals at E14-17 [Fig. 4(a)] which increase in intensity between P0 and P15. The adult retina contains a mixture of intensely and weakly stained RGCs. RGCs surviving after optic nerve transection (which is known to cause cell death) were weakly stained. RGCs in rats which received a peripheral nerve graft (Aguayo et al., 1991; Jung et al., 1997), however, had intense in situ hybridization signals in RGCs which had regenerating axons in the graft [Fig. 4(b)]. Axon-regenerating RGCs were identified by their content of HRP [Fig. 4(b)], which is applied to the axons in the graft 28 days after surgery, as was described earlier (Jung et al., 1997). Thus, during graft-assisted axon regeneration, rat RGCs increase synthesis of reggie-1 and reggie- 2 mRNAs. This correlates with the up-regulation of both mRNAs in axon-regenerating RGCs in fish (Schulte et al., 1997).

Figure 3 Northern blot analysis of the tissue-specific expression of reggie. Rat reggie-1 and rat reggie-2 mRNAs are expressed in the rat brain during embryogenesis (E16 and E19), postnatal development (P0, P3, and P9), and adulthood. Both mRNAs are also detected (with ${ }^{32} \mathrm{P}-\mathrm{UTP}-\mathrm{la}-$ beled reggie-1 and -2 riboprobes) in the skin of rat embryos (E19). A DIG-labeled riboprobe of rat GAPDH was applied to the same membranes to obtain an estimate of the relative amount of RNA loaded (mRNA sizes in kilobases are shown at the left).

orientation is consistent with immunolocalization data (see below). Also like flotillin-1 and -2, reggie-2 and -1 possess multiple potential phosphorylation sites (Bickel et al., 1997). $\alpha$-Helices and $\beta$-sheet domains are predicted for flotillin-1 and reggie-2 as well as for reggie-1 (Schroeder et al., 1994). Rat and fish reggie-1 and -2 share repeats of A, E, A, E, which are also found in ESA

\section{Reggie-1 and Reggie-2 Are Associated with the Plasmamembrane}

To study the cellular distribution of reggie-1 and reggie-2 proteins, primary cultures of rat and fish neurons (rat DRGs and rat and fish retinal explants), rat astrocytes, PC-12 cells, and fish epithelioma cells were subjected to immunocytochemistry. Cells were exposed to $\mathrm{mAB}$ anti-ESA/reggie-1, a newly generated $\mathrm{mAB}$, anti-goldfish reggie-2, and purified $\mathrm{ABs}$ against reggie- 2 .

The specificity of all antibodies was verified in immunoblots (Fig. 2) with recombinant goldfish reggie-1 and reggie-2 (from transformed E. coli), with 

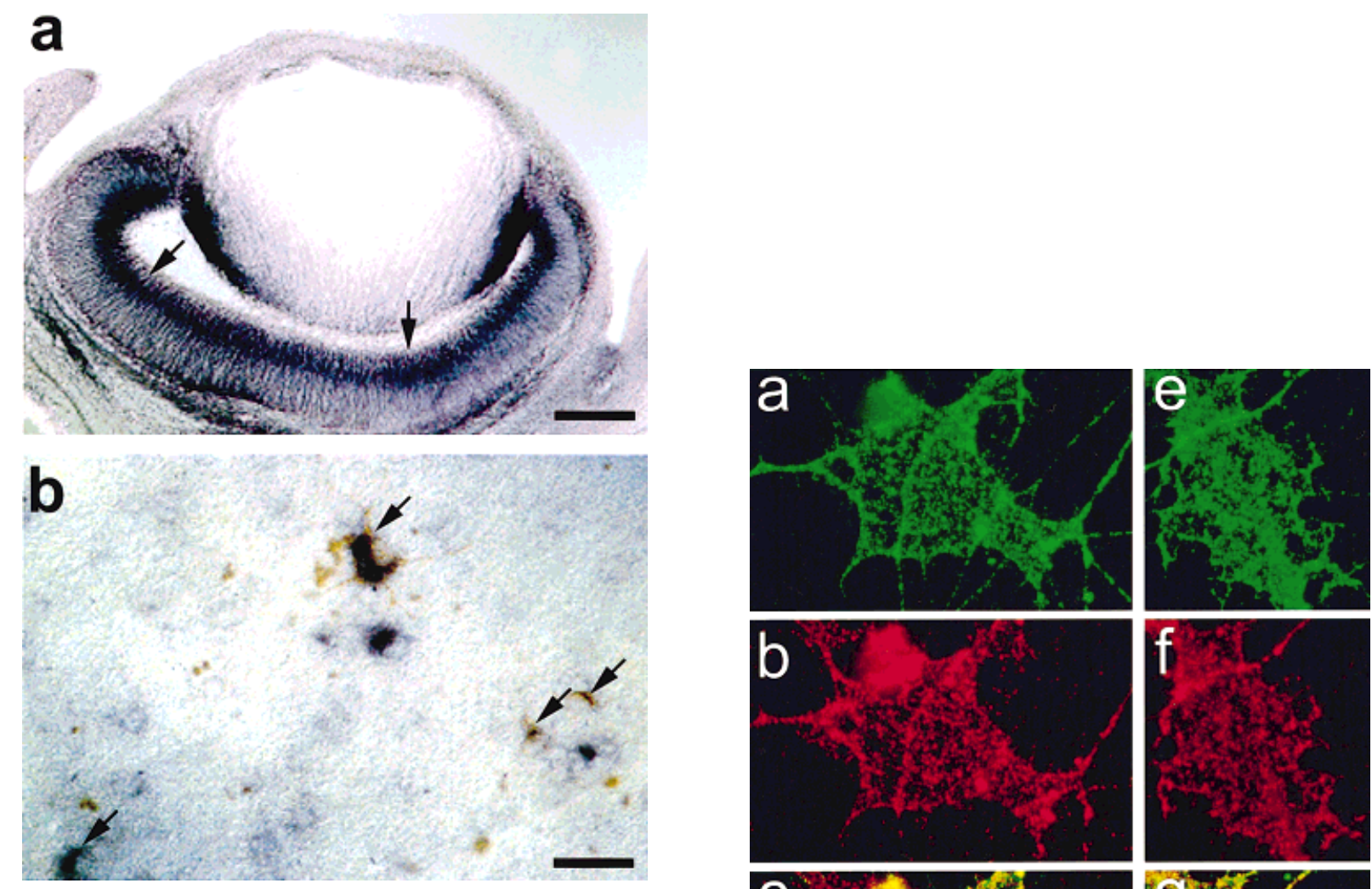

Figure 4
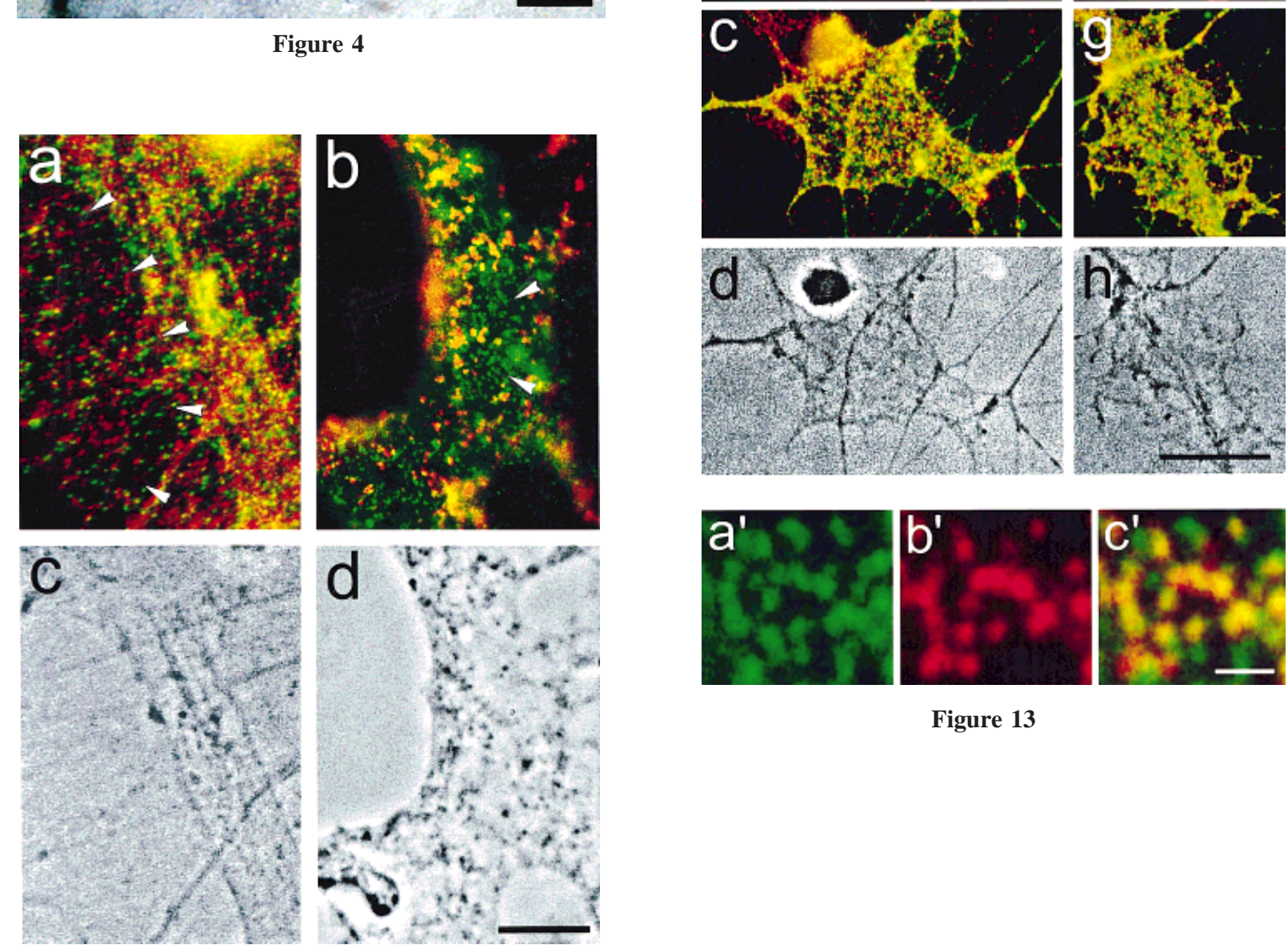

Figure 13

Figure 6 
homogenates of rat and goldfish brains, and with the various cells used for localizing the proteins by immunofluorescence.

Monoclonal antibody anti-ESA recognized recombinant reggie-1 (but not reggie-2) and $47 \mathrm{kD}$ reggie-1 in both rat and goldfish tissue and cell homogenates [Fig. 2(a)]. Polyclonal anti-reggie-2 ABs bind to recombinant reggie-2 (but not to reggie-1) and revealed $47 \mathrm{kD}$ reggie-2 in goldfish and the rat [Fig. 2(b)]. For immunostaining, all cell types analyzed required fixation and permeabilization achieved by a brief exposure of the cultured cells to ice-cold methanol (see Materials and Methods). Methanol treatment provides antibodies access to intracellular epitopes, as has previously been shown in the case of anti-neurofilament and anti-glial fibrillary acidic protein (GFAP) staining (Paschke et al., 1992; Lang et al., 1996; Lang and Stuermer, 1996). Live cells remained unlabeled with $\mathrm{mABs}$ and polyclonal $\mathrm{ABs}$, indicating that the epitopes recognized by the antibodies must lie intracellularly or within the cell membrane. The alternative procedure, i.e., fixation of cells with PFA and subsequent exposure to $0.1 \% \mathrm{TX}-100$, gave comparable results, except that the punctate staining pattern (see below) was less distinct.
All cells exhibited a punctate plasmalemma-associated immunofluorescence over their entire extent after exposure to antibodies against reggie-1 and -2 . In DRG neurites [Fig. 5(c,d)], regenerating goldfish [Fig. 5(a,b)], and rat RGC axons, the punctate plasmalemma-associated immunofluorescence with both $\mathrm{mAB}$ anti-ESA/reggie-1 and polyclonal anti-reggie-2 ABs extended along the axons, including the growth cones and filopodia. This shows that reggie- 1 and -2 accompany axon growth and regeneration, and implies a function during axon elongation. The punctate distribution of reggie-1 and -2 was observed in the cell membrane over the soma and cellular processes in PC-12 cells [Fig. 5(e,f)] and astrocytes [Fig. 5(g,h)].

To determine if and to what extent reggie- 1 and reggie-2 are colocalized in the plasmamembrane, flattened DRG growth cones were selected for analysis [Fig. 5(c, $\left.\left.\mathrm{c}^{\prime}, \mathrm{d}, \mathrm{d}^{\prime}\right)\right]$. A computer-assisted quantification of red and green fluorescent dots and, after image fusion, of the resulting yellow dots was performed (Mayor et al., 1994) (see Materials and Methods). These values (Table 1) were compared to random colocalization values (Mayor et al., 1994). Cells exposed to $\mathrm{mAB}$ anti-ESA/reggie-1 and polyclonal antireggie-2 $\mathrm{ABs}$ and the relevant red and green fluores-

Figure 4 Expression of reggie mRNA in the rat retina. In situ hybridization with a DIG-labeled cRNA probe of reggie-2 shows intense signals in the retinal ganglion cell layer (arrows), here in a cross section through the eye at E16. Scale bar $=160 \mu \mathrm{m}$. (b) RGCs in adult rats which regenerate an axon into a peripheral nerve graft exhibit intense in situ hybridization signals (in a segment of a retina whole mount). The cytoplasma of these neurons (arrows) is labeled by HRP, which was applied to regenerating axons in the graft. Scale bar $=40 \mu \mathrm{m}$.

Figure 6 Comparison of the punctate anti-caveolin and anti-ESA/reggie-1 immunofluorescence on rat astrocytes. (a) Anti-caveolin puncta (red) and anti-ESA/reggie-1 micropatches (green) are distributed evenly over its processes. In the flat process (marked by arrowheads), the vast majority of red and green dots lie separately. Only where thickened membrane protrusions occur are red and green dots occasionally superimposed (yellow) on the same cell. (b) After exposure to filipin, the anti-caveolin immunoreactive puncta (red) are merged into larger conglomerates with unlabeled areas in between. The even distribution of anti-ESA/reggie-1 micropatches (green) is preserved in the filipin-treated astrocyte, and immunofluorescent puncta are seen in areas free of anti-caveolin staining (arrowheads). (c,d) Phase-contrast photomicrograph of the astrocytes shown in (a,b). Scale bar $=10 \mu \mathrm{m}$.

Figure 13 Colocalization of Thy-1 and F3 after antibody crosslinking and reggie-1 and -2. (a) Anti-ESA/reggie-1 mAB produces a punctate immunofluorescence in DRG growth cones. (b) Exposure to anti-F3 ABs leads to a punctate distribution of the CAM in the same growth cone. (c) Yellow dots in the fused images are indicative of colocalization of the GPI-linked CAM and reggie-1. (d) Phase-contrast image of the growth cone in (a-c). (e) Exposure to anti-Thy-1 mAB results in a punctate fluorescence on the DRG growth cone. The density of the puncta is higher than with F3. (f) A punctate distribution of reggie-2 is evidenced by anti-reggie- 2 AB immunofluorescence. The density of reggie- 2 puncta is higher than that of reggie- 1 dots. (g) The fusion of images (e) and (f) and the resulting yellow dots show colocalization of Thy-1 clusters and reggie-2. (h) Phase-contrast photomicrograph of the growth cone in $(\mathrm{e}, \mathrm{f})$. Scale bar $=10 \mu \mathrm{m} .\left(\mathrm{a}^{\prime}, \mathrm{b}^{\prime}, \mathrm{c}^{\prime}\right)$ Higher magnification of $\left(a^{\prime}\right)$ the green fluorescent anti-ESA/reggie-1 puncta and $\left(b^{\prime}\right)$ the red fluorescent anti-F3 puncta [from $(a, b)$, respectively]. ( $\left.c^{\prime}\right)$ The fusion of the images [from (c)]. Scale bar $=1 \mu \mathrm{m}$. 

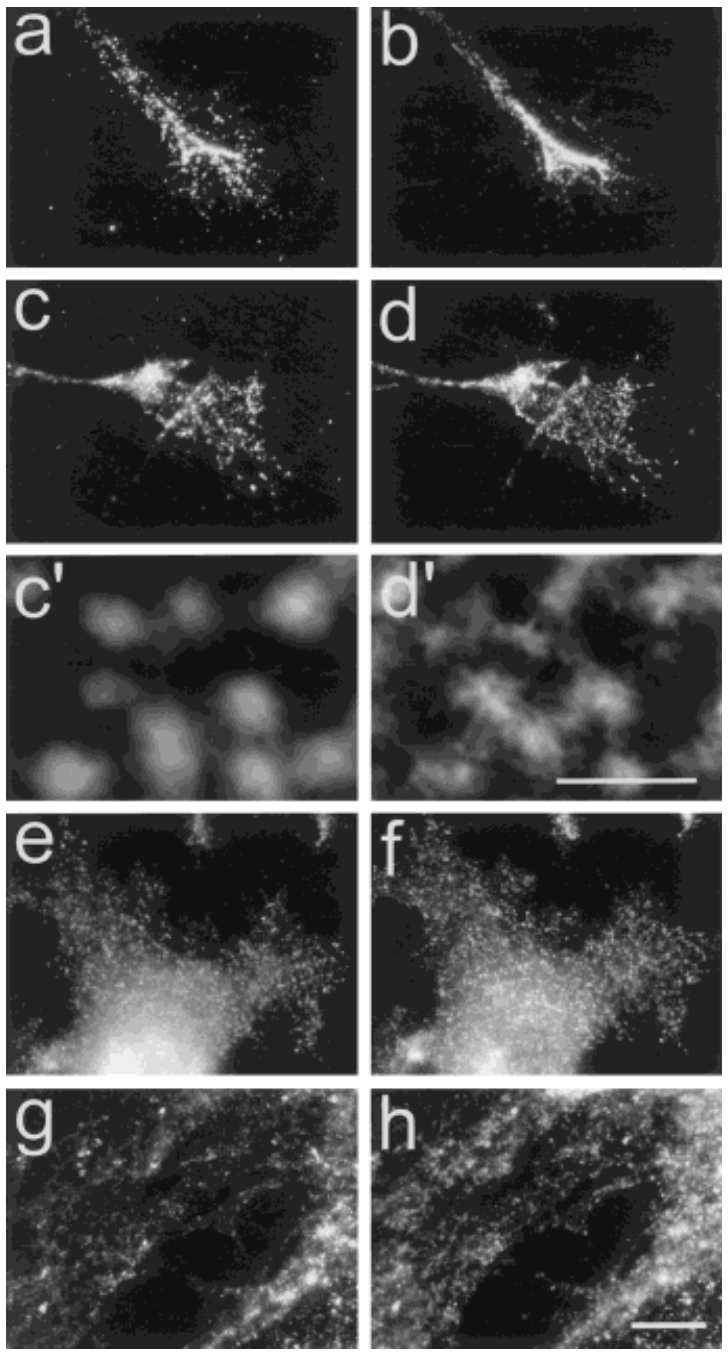

Figure 5 Punctate distribution of reggie-1 and reggie-2 in fish and mammalian cells. Both $\mathrm{mAB}$ anti-ESA/reggie-1 $\left(\mathrm{a}, \mathrm{c}, \mathrm{c}^{\prime}, \mathrm{e}, \mathrm{g}\right)$ and anti-reggie-2 $\mathrm{ABs}\left(\mathrm{b}, \mathrm{d}, \mathrm{d}^{\prime}, \mathrm{f}, \mathrm{h}\right)$ produce a punctate immunofluorescence in goldfish RGC growth cones $(\mathrm{a}, \mathrm{b})$, in growth cones of rat DRGs $(\mathrm{c}, \mathrm{d})$, soma and processes of PC-12 cells (e,f), and in rat astrocytes (g,h). The density of reggie-2 dots is slightly higher than the reggie-1 dots. Scale bar $=10 \mu \mathrm{m}$. $\left(\mathrm{c}^{\prime}, \mathrm{d}^{\prime}\right)$ show reggie- 1 and reggie-2 puncta [from (c,d), respectively] at a higher magnification. Scale bar $=1 \mu \mathrm{m}$.

cent secondary antibodies exhibited a substantial number of overlapping (i.e., yellow dots) (Table 1). In all cells examined, the density of red anti-reggie-2 dots was higher than that of green anti-reggie-1 dots (shown in black and white in Fig. 5). A total of $87 \%$ of the reggie-2 dots coclustered with anti-reggie-1 dots, and $73 \%$ of the anti-reggie-1 dots coclustered with anti-reggie-2 dots (Table 1). These values are significantly higher than the random colocalization values of $29 \%$ and $27 \%$, respectively. Thus, a sub- stantial fraction of reggie-1 and reggie-2 are coclustered in micropatches in the plasmamembrane.

In rat astrocytes, the patchy immunofluorescence with both anti-ESA/reggie-1 and anti-reggie-2 ABs is reminiscent of the dotted distribution of anti-caveolin ABs on nonneuronal cells (Mayor et al., 1994; Cameron et al., 1997).

To determine if reggie is associated with caveolae, as was suggested by Bickel et al. (1997), we performed double-immunostaining experiments with $\mathrm{mAB}$ anti-ESA/reggie-1 and anti-caveolin $\mathrm{ABs}$ on astrocytes [Fig. 6(a,b)], which are anti-caveolin AB positive (Cameron et al., 1997). The red anti-caveolin immunofluorescent puncta in the astrocyte plasmamembrane were mostly separate from the green immunofluorescent anti-ESA/reggie-1 dots, particularly in the flat membraneous process (Fig. 6). Yellow dots occurred over membrane protrusions, but can be attributed to the physical overlap of several membranes and not to colocalization of antigens. Caveolae and the pattern of anti-caveolin AB immunofluorescence can be disrupted by filipin (Rothberg et al., 1990, 1992), which binds cholesterol. While filipin-treated astrocytes exhibited larger conglomerates and areas free of anti-caveolin immunofluorescence [Fig. 6(b)], they preserved the punctate distribution of anti-ESA/ reggie-1 $\mathrm{mAB}$. Thus, reggie-1 does not appear to be localized in caveolae, but occurs in separate microdomains.

\section{Tests for the Presence of Caveolae in Neurons}

While caveolae are known to be present in astrocytes (Parton, 1996; Cameron et al., 1997), there are conflicting reports about the presence of caveolae and caveolin in neurons (Shyng et al., 1994; Gorodinsky and Harris, 1995; Ying et al., 1992; Hermey et al., 1995). Because none of the neural cell types of interest in our study have been specifically analyzed, ultrastructural analysis was undertaken to determine whether neurons (RGCs, DRGs, and PC-12 cells) exhibit plasmamembrane invaginations corresponding in size and distribution to caveolae reported in the literature (Parton, 1996; Cameron et al., 1997). Astrocytes served as controls to define the size of these invaginations and their dependence on the fixation employed. The same cells were subjected to immunostaining and immunoblot analyses with anti-caveolin AB. While anti-caveolin AB recognized the 21-kD protein in immunoblots with rat oligodendrocytes and astrocytes [Fig. 2(e)], it failed to reveal this protein in PC-12 cells [Fig. 2(e)]. Primary cultures of rat DRGs always contain a small number of satellite cells that are anti-caveolin $\mathrm{AB}$ positive, so that immunoblots 
Table 1 Quantification of Immunofluorescent Micropatches in DRG Growth Cones and Determination of Colocalization Values

\begin{tabular}{|c|c|c|c|c|}
\hline & No. of Labeled Micropatche & $\mathrm{n}^{2}$ Growth Cone Area & & $n$ \\
\hline ESA/reg-1 & reg-2 & $\begin{array}{c}\text { Colocalization: } \\
\text { ESA/reg-1 and reg-2 }\end{array}$ & $\begin{array}{c}\text { Random } \\
\text { Colocalization } \\
\text { Value }\end{array}$ & \\
\hline $2.4 \pm 0.4(100 \%)$ & $2.9 \pm 0.5(100 \%)$ & $\begin{array}{c}2.1 \pm 0.4(87 \%)^{*} \\
(73 \%)\end{array}$ & $\begin{array}{c}0.7 \pm 0.3(29 \%)^{*} \\
(27 \%)\end{array}$ & 50 \\
\hline ESA/reg-1 & F3 & $\begin{array}{l}\text { Colocalization: } \\
\text { ESA/reg-1 and F3 }\end{array}$ & $\begin{array}{c}\text { Random } \\
\text { Colocalization } \\
\text { Value }\end{array}$ & \\
\hline $2.2 \pm 0.4(100 \%)$ & $2.3 \pm 0.5(100 \%)$ & $\begin{array}{c}1.4 \pm 0.3(64 \%)^{*} \\
(61 \%)\end{array}$ & $\begin{array}{c}0.7 \pm 0.3(32 \%)^{*} \\
(30 \%)\end{array}$ & 50 \\
\hline reg-2 & Thy-1 & $\begin{array}{l}\text { Colocalization: } \\
\text { reg-2 and Thy-1 }\end{array}$ & $\begin{array}{c}\text { Random } \\
\text { Colocalization } \\
\text { Value }\end{array}$ & \\
\hline $2.8 \pm 0.5(100 \%)$ & $3.1 \pm 0.6(100 \%)$ & $1.6 \pm \underset{(50 \%)}{0.4(56 \%)^{*}}$ & $\begin{array}{c}1.2 \pm 0.3(43 \%)^{*} \\
(40 \%)\end{array}$ & 30 \\
\hline
\end{tabular}

Immunolabeling was performed pairwise with antibodies against ESA/reggie-1 and -2 (ESA/reg-1 and reg-2, respectively) and antibodies against F3 and Thy-1. Numbers of dots (means \pm S.D.) immunolabeled with each one of the two antibodies were set to $100 \%$ and coincident dots obtained with the other antibody were set into relation. Colocalization values of each pair were compared to the random colocalization value. $n=$ number of evaluated membrane fields $\left(9 \mu \mathrm{m}^{2}\right)$.

$* \alpha<.005$ in Student's $t$ test.

with such cultures were inappropriate for determining whether DRG neurons express caveolin. However, unlike the satellite cells, DRG neurons were not stained by anti-caveolin AB (Fig. 7).

Ultrathin sections revealed two populations of membrane-bound vesicles (Table 2): small, clear vesicles of $55 \times 80-\mathrm{nm}$ size which are closed, and putative caveolae which are open invaginations. $\mathrm{Pu}-$ tative caveolae were defined on the basis of size $(\geq 75$ $\times 100 \mathrm{~nm}$ ) and can be seen in Figure 8 . The size distribution of both vesicular structures is clearly different, as illustrated by the histograms in Figure 9 .

The overlap is small, and only one structure seen in neurons was the size of caveolae. This was considered not to represent a caveola (Table 3), but a larger form of the small-sized vesicle population. Plasmalemmal invaginations of $80 \times 120 \mathrm{~nm}$ (Table 2), i.e., caveolae, were found in astrocytes in agreement with the size distribution of established caveolae (Parton, 1996). Sizes did not significantly differ after chemical fixation $\left(2 \% \mathrm{OsO}_{4}\right)$ or cryofixation (Table 2). A quantification in randomly selected fields of these structures yielded values of $0.3-1.10$ caveolae/ $\mu \mathrm{m}^{2}$ plasmalemmal surface depending on the preparation protocol (Table 3).

No caveolae were detected in ultrastructural analysis of NGF-treated and process-bearing PC-12 cells (anti-caveolin $\mathrm{AB}$ negative). Here, a much larger cell membrane area was scanned, again in randomly taken fields, and the occurrence of caveolae (defined above by shape and size) was practically 0 (Tables 2 and 3 ).

In cell cultures from rat DRGs, DRG neurons possessed long neurites (immunoreactive with $\mathrm{ABs}$ against L1 and neurofilaments but not with anticaveolin) and were morphologically distinct from the nonneuronal anti-caveolin-positive satellite cells (Fig. 7). In ultrathin sections through cells in parallel cultures, the abundant long, thin processes (DRG neurites) were easily distinguished from larger profiles of the occasional satellite cells. The long thin processes exhibit small vesicles of $51 \times 65 \mathrm{~nm}$ (width $\times$ length) at the plasmamembrane with a density of $0.6-2.1 /$ $\mu \mathrm{m}^{2}$. Invaginations of the size and shape characteristic of caveolae (Fig. 8) were not seen, although a much larger area of plasmamembrane was analyzed (Tables 2 and 3, Fig. 10). They were, however, seen in occasional sections through satellite cells.

Caveolae were also absent from goldfish RGCs subjected to the same morphometric analysis. RGC somata and RGC axons exhibited only small vesicles of $55 \times 75 \mathrm{~nm}$ (Tables 2 and 3 ) at their plasmamembrane, but invaginations of the size and shape of caveolae were essentially absent.

The fact that PC-12 cells, rat DRG neurons, and 

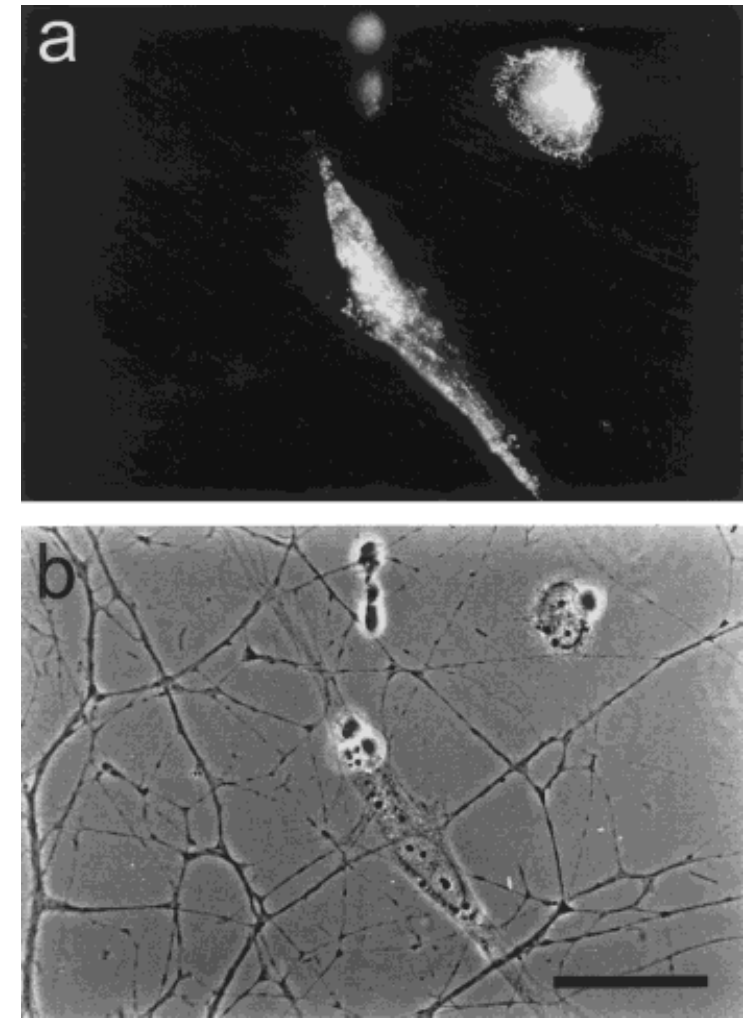

Figure 7 Caveolin is absent from DRG neurons. Anticaveolin immunofluorescence photomicrographs of DRG neurites and occasional satellite cells (a) and the corresponding phase contrast images (b). The satellite cells are anti-caveolin positive but the DRG neurites are unstained. Scale bar $=50 \mu \mathrm{m}$.

goldfish RGCs do not have caveolae excludes the possibility that reggie- 1 and reggie- 2 represent caveolar proteins. To determine where reggie-1 is localized, ultrathin sections of fixed DRG neurons were exposed to anti-ESA/reggie-1 mAB and gold-coupled secondary antibodies (Au-AB). Two different fixation protocols were used [(c) and (d) in Materials and Methods]. While method (d) is generally used in caveolae immunocytochemistry (Chang et al., 1994; Cameron et al., 1997), we achieved improved ultrastructural preservation and similar labeling density with method (c) (Ying et al., 1992). The distribution of gold particles was compared to that in control sections treated with Au-AB only (Table 4). While single gold particles were found along the cell membrane in controls, small clusters of gold particles (13.6 times over control) were recognized adjacent to the plasmamembrane after exposure to primary and secondary antibodies (Fig. 11). These were not associated with any morphologically distinct structures. These data confirm that reggie- 1 is associated with the plasmamembrane of DRG neurons and apparently occurs in clusters.

\section{GPI-Linked Proteins Cocluster with Plasmamembrane-Associated Reggie-1 and Reggie-2}

Reggie-1 and -2 are biochemically enriched in the same fraction as caveolin (Bickel et al., 1997) and GPI-anchored membrane proteins (Lisanti et al., 1994). Thus, they may represent foci for the sequestration of GPI-linked proteins (Mayor et al., 1994, Olive et al., 1995), particularly in neurons, which lack caveolae and caveolin (the current study; Shyng et al., 1994). To confirm that reggie- 1 and -2 , as well as GPI-linked CAMs, are enriched in the fraction that contains caveolin when prepared from the rat brain, such fractions were obtained and probed with the relevant antibodies. Moreover, such fractions were also prepared from PC-12 cells which lack caveolae and caveolin to demonstrate the biochemical correlate of detergent resistent fractions (i.e., DIGs) does exist in neurons and contains reggie- 1 and -2 but not caveolin. PC-12 cells were used in these experiments because no caveolin-positive glial or satellite cells contaminate the cultures (see above).

When TX-100 soluble and insoluble (buoyant) membrane fractions are compared (Fig. 12), reggie-1 and -2 as well as GPI-linked CAMs were enriched in the buoyant fraction in preparations from both the rat brain [Fig. 12(a)] and PC-12 cells [Fig. 12(b)]. The buoyant fraction from PC-12 cell membranes [Fig. 12(b)], however, did not show anti-caveolin immunoreactivity, as expected. Consistent with the notion that $s r c$ family tyrosine kinases become enriched in TX100 insoluble fractions, the anti-src antibody revealed the presence of this kinase in the boyant fraction of PC-12 cells [Fig. 12(b)].

This is consistent with the notion that DIGs exist in the absence of caveolin and caveolae (Harder and Simons, 1997). Moreover, according to these biochemical data, reggie- 1 and -2 could participate in the formation of the morphological correlate of DIGs, i.e., micropatches.

To test this hypothesis, we employed ABs against the GPI-anchored CAMs F3 and Thy-1 in crosslinking assays and examined DRG neurons to determine whether the resulting anti-F3 and anti-Thy-1 immunofluorescent micropatches are colocalized with antiESA/reggie-1 and anti-reggie-2 puncta. DRG neurons were used instead of PC-12 cells because they express Thy 1 and F3, and because we prefer primary neurons over the cell line for these tests.

When live cells were exposed to antibodies against the GPI-linked CAMs at $37^{\circ} \mathrm{C}$ for $45 \mathrm{~min}$, the punctate pattern typical of clustered proteins (Ying et al., 1992; Mayor et al., 1994) became evident (Fig. 13). The same pattern was observed when cells were 
Table 2 Sizes of Small Vesicles and Caveolae in Electron Micrographs of the Various Cell Types after Fixation in $\mathrm{OsO}_{4}[\operatorname{Method}(\mathrm{b})]$ or after Cryofixation $[\operatorname{Method}(\mathrm{a})]$

\begin{tabular}{|c|c|c|c|c|c|c|c|c|}
\hline \multirow[b]{2}{*}{ Cell Type } & \multirow[b]{2}{*}{ Preparation } & \multicolumn{5}{|c|}{ Organelle Size } & \multirow[b]{2}{*}{$N$} & \multirow[b]{2}{*}{ hp } \\
\hline & & & Small & cles & $\mathrm{Ca}$ & & & \\
\hline \multirow[t]{6}{*}{ Astrocytes } & $\mathrm{OsO}_{4}, 0^{\circ} \mathrm{C}$ & & & & & & & \\
\hline & Width & 54 & \pm 2 & $n=21$ & $90 \pm 3$ & $n=9$ & 15 & 422 \\
\hline & Height & 82 & \pm 5 & & $126 \pm 6$ & & & \\
\hline & Cryofixation & & & & & & & \\
\hline & Width & 61 & \pm 4 & $n=17$ & $80 \pm 9$ & $n=5$ & 15 & 451 \\
\hline & Height & 75 & \pm 5 & & $115 \pm 11$ & & & \\
\hline \multirow[t]{3}{*}{ PC-12 cells } & $\mathrm{OsO}_{4}, 0^{\circ} \mathrm{C}$ & & & & & & & \\
\hline & Width & 54 & \pm 3 & $n=20$ & (67) & $n=1$ & 15 & 433 \\
\hline & Height & 79 & \pm 5 & & (149) & & & \\
\hline \multirow[t]{3}{*}{ Satellite cells (rat) } & $\mathrm{OsO}_{4}, 0^{\circ} \mathrm{C}$ & & & & & & & \\
\hline & Width & 64 & \pm 2 & $n=26$ & $83 \pm 3$ & $n=26$ & 15 & 517 \\
\hline & Height & 89 & \pm 3 & & $126 \pm 3$ & & & \\
\hline \multirow[t]{6}{*}{ Neurons (rat DRG) } & $\mathrm{OsO}_{4}, 0^{\circ} \mathrm{C}$ & & & & & & & \\
\hline & Width & 48 & \pm 5 & $n=10$ & & & 46 & 371 \\
\hline & Height & 64 & \pm 4 & & & & & \\
\hline & Cryofixation & & & & & & & \\
\hline & Width & 53 & \pm 4 & $n=17$ & (79) & $n=1$ & 17 & 1073 \\
\hline & Height & 66 & \pm 5 & & (103) & & & \\
\hline \multirow[t]{6}{*}{ Neurons (fish RGC) } & $\mathrm{OsO}_{4}, 0^{\circ} \mathrm{C}$ & & & & & & & \\
\hline & Width & 50 & \pm 2 & $n=40$ & $(80)$ & $n=1$ & 53 & 836 \\
\hline & Height & 81 & \pm 4 & & $(105)$ & & & \\
\hline & Cryofixation & & & & & & & \\
\hline & Width & 58 & \pm 5 & $n=5$ & & & 36 & 450 \\
\hline & Height & 68 & \pm 11 & & & & & \\
\hline
\end{tabular}

$n=$ number of vesicles (small and caveolae); \pm S.E.M.; $N=$ number of cells analyzed; hp $=$ hit points for cell membrane area correction (see Materials and Methods). Numbers in parentheses are single observations and represent the spillover of the two vesicle sizes.

stained at $4^{\circ} \mathrm{C}$ for $1 \mathrm{~h}$ or when the antibodies were applied to the cells after fixation in PFA, which excludes the possibility that the fluorescent patches represent internalized ABs (Mayor et al., 1994). When cells treated in this way were fixed and permeabilized in methanol and then stained with $\mathrm{mAB}$ anti ESA/ reggie-1 or anti-reggie-2 ABs, they displayed a punctate distribution of F3 and reggie-1 [Fig. 13(a-d)] and Thy-1 and reggie-2 [Fig. 13(e-h)]. Again, the flattened DRG growth cones were chosen for direct comparison of the reggie-1 with $\mathrm{F} 3$, and reggie-2 with Thy- 1 puncta and for the determination of their overlap. Combination of the images [Fig. 13( $\left.a^{\prime}, b^{\prime}, c^{\prime}\right)$ for reggie-1 and $\mathrm{F} 3$ ] shows that many green and red fluorescent dots are colocalized, indicating that many of the crosslinked GPI-linked CAMs cocluster with reggie (Table 1). These images also reveal that the density of both anti-reggie-2 ABs and anti-Thy-1 $\mathrm{mAB}$ positive puncta is higher (Fig. 13 and Table 1) than the density of dots of the F3 and reggie-1 pair.

The quantification of GPI-anchored CAM and reggie coclusters (Table 1) was performed as mentioned above (Mayor et al., 1994): 64\% of the anti-F3 dots were colocalized with anti-reggie- 1 dots, and $61 \%$ of the anti-reggie-1 dots had anti-F3 dots directly associated with them. Random colocalization values were $32 \%$ and $30 \%$, respectively. A total of $56 \%$ of antiThy- 1 dots coclustered with anti-reggie- 2 dots and $50 \%$ of the reggie- 2 dots were colocalized with Thy- 1 dots. Here, the random colocalization values are higher- $43 \%$ and $40 \%$, respectively-because of the higher density of Thy- 1 and reggie- 2 in the growth cones.

Thus, significant amounts of F3 and Thy-1 are coclustered with reggie micropatches in neuronal growth cones, suggesting that reggie micropatches represent foci to which activated GPI-linked CAMs preferentially associate.

\section{DISCUSSION}

Light-microscopic and EM immunolabeling techniques demonstrate that reggie proteins are localized 


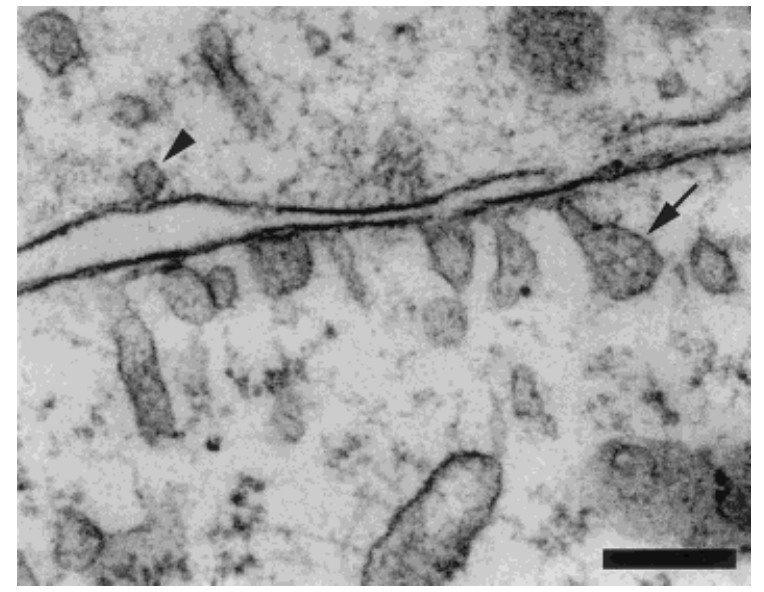

Figure 8 Electronmicrograph of astrocytes showing caveolae (after $\mathrm{OsO}_{4}$ fixation). One of several flask-shaped plasmamembrane invaginations, i.e., a caveola, is marked by an arrow. A smaller sized vesicle is indicated for comparison (arrowhead). Scale bar $=0.2 \mu \mathrm{m}$.

at the plasmamembrane of neurons (including their axons and growth cones) where they associate into clusters of $2.2-2.5 / \mu \mathrm{m}^{2}$. The distribution of reggie-1 and -2 in the plasmamembrane indicates microclusters with which GPI-linked cell-surface proteins (the CAMs F3 and Thy-1) preferentially associate after antibody crosslinking. Activated GPI-linked surface proteins tend to assemble in microdomains which, depending on the cell type analyzed, represent caveolae (Ying et al., 1992; Sargiacomo et al., 1993; Mayor et al., 1994) or noncaveolar subcompartments (Liu et al., 1997; Harder and Simons, 1997). Although it has been proposed otherwise (Bickel et al., 1997; Galbiati et al., 1998), reggie-1 and -2 are not caveolae-associated membrane proteins, as the neurons analyzed here do not possess caveolae or caveolin. This was shown by quantitative ultrastructural analysis (RGCs, DRGs, and PC-12 cells) and, where applicable, by anticaveolin $\mathrm{AB}$ immunoblot (PC-12 cells) and immunocytochemical analyses (DRGs and PC-12 cells). Moreover, in astrocytes which do exhibit caveolae (Parton, 1996; Cameron et al., 1997; the current study), reggie micropatches persist after exposure to filipin, which causes the caveolin-positive microdomains to dissociate (Rothberg et al., 1990, 1992). This confirms that reggie micropatches are independent of caveolae. Based on their distribution, reggie proteins therefore define plasmamembrane micropatches, where specific GPI-linked CAMs preferentially cluster after antibody crosslinking.

Molecular cloning of rat reggie-1 and -2 and sequence comparison demonstrates a surprisingly high degree of identity between the fish and mammalian proteins (Schroeder et al., 1994; Schulte et al., 1997;

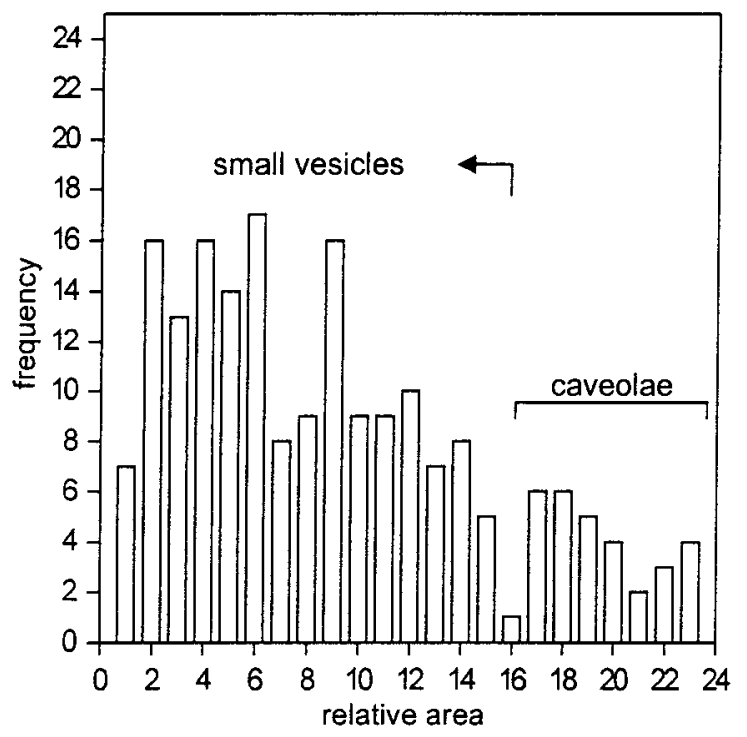

Figure 9 Histogram showing the size distribution of small vesicles and caveolae at the plasmamembrane of neurons and astrocytes. The size of small vesicles and large vesicles (caveolae) was determined (Table 2) and translated into relative area values (abscissa). The ordinate gives values of the frequency with which vesicles of various sizes were found. Caveolae fall into size categories 16-23, and small vesicles in categories $1-14$. There is some spillover of the two vesicle populations at relative area size 16. By their larger size, caveolae represent a distinct group of plasmamembrane invaginations. The frequency of small vesicles and caveolae depending on cell type and treatment is given in Table 2.

Bickel et al., 1997). Even though MESA and ESA lack the $\mathrm{N}$ terminus identified here in rat reggie-1 (and previously found in the goldfish protein) (Schulte et al., 1997), EST clones corresponding to the rat reg-

Table 3 Frequency Distribution of Caveolae and Small Vesicles

\begin{tabular}{llcc}
\hline & & \multicolumn{2}{c}{$\begin{array}{c}\text { Organelles per } \mu \mathrm{m}^{2} \\
\text { Cell Membrane }\end{array}$} \\
\cline { 3 - 4 } \multicolumn{1}{c}{ Cell Type } & Preparation & $\begin{array}{c}\text { Small } \\
\text { Vesicles }\end{array}$ & Caveolae \\
\hline Astrocytes & $\mathrm{OsO}_{4}, 0^{\circ} \mathrm{C}$ & 2.45 & 1.05 \\
& $\mathrm{Cryofixation}$ & 1.77 & 0.26 \\
PC-12 cells & $\mathrm{OsO}_{4}, 0^{\circ} \mathrm{C}$ & 2.27 & $(0.10)$ \\
Satellite cells (rat) & $\mathrm{OsO}_{4}, 0^{\circ} \mathrm{C}$ & 2.85 & 2.14 \\
Neurons (rat DRG) & $\mathrm{OsO}_{4}, 0^{\circ} \mathrm{C}$ & 1.33 & 0.00 \\
& $\mathrm{Cryofixation}$ & 0.83 & $(0.04)$ \\
Neurons (fish RGC) & $\mathrm{OsO}_{4}, 0^{\circ} \mathrm{C}$ & 3.46 & $(0.09)$ \\
& $\mathrm{Cryofixation}$ & 0.82 & 0.00 \\
\hline
\end{tabular}

The occurrence of small vesicles and of caveolae per square micrometer cell membrane is listed for the five different cell types analyzed and in dependence of the type of fixation applied. Values in parentheses indicate possible spillover between the two vesicle types. 

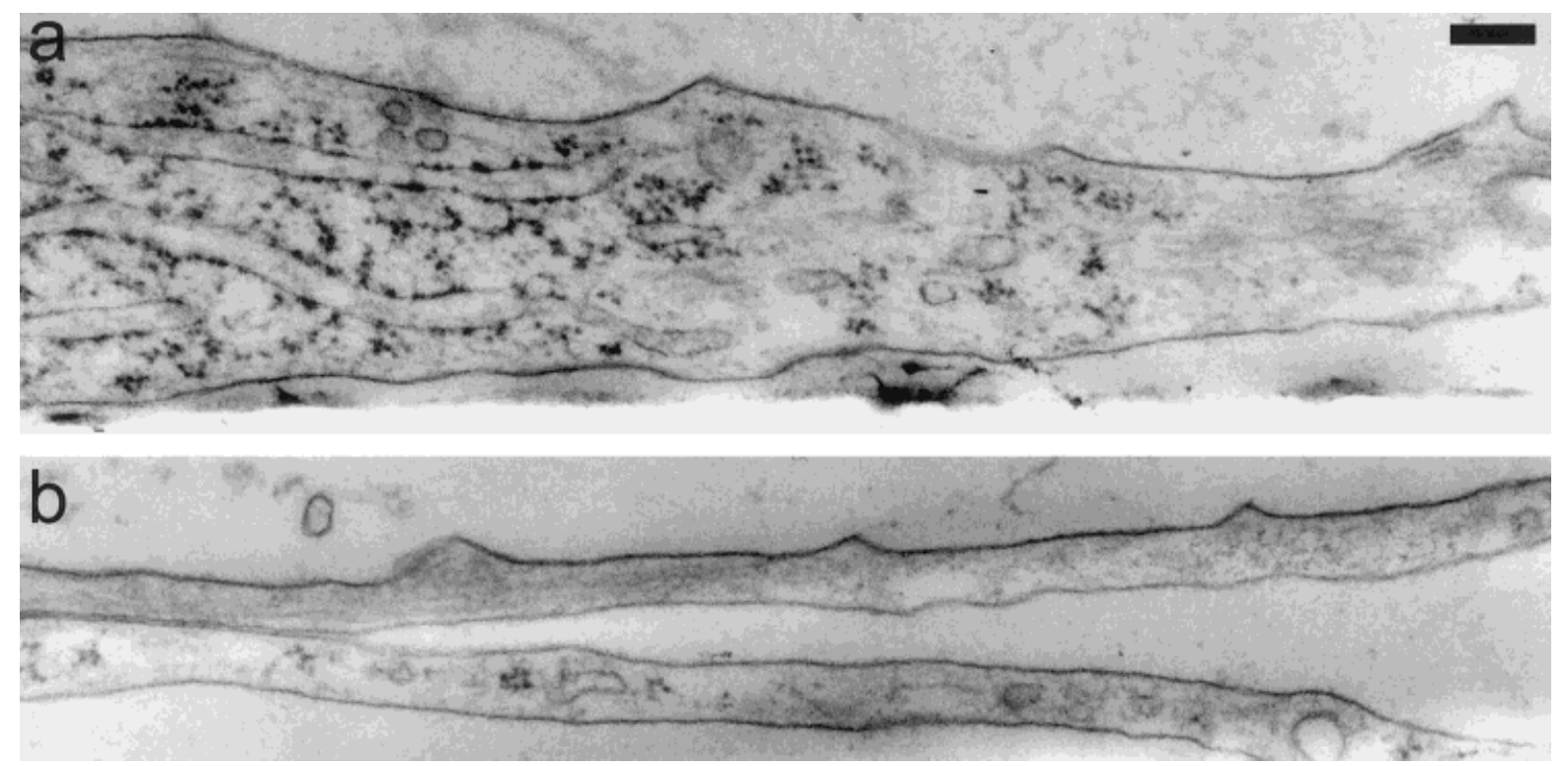

Figure 10 Electronmicrograph of a cryofixed DRG neurite at increasing distances from the soma. There are no caveolae-type invaginations at the plasmamembrane of DRG neurons, either close to the soma (a) or in neurites far away from the soma (b). Scale bar $=0.2 \mu \mathrm{m}$.

gie-1 $\mathrm{N}$ terminus strongly suggests the existence of the larger protein, i.e., reggie-1 in mouse and humans. Moreover, a corresponding EST clone of Drosophila was found in the databases. A recent publication by Galbiati et al. (1998) identified flotillin-1 and ESA homologs in Drosophila. The high degree of sequence conservation across species may mean that reggie-1 and -2 (alias ESA/flotillin-2 and flotillin-1) have related functions in fish and mammals and also perhaps in flies, and that functional or structural parameters require sequence conservation.

How reggie- 1 and -2 associate with or integrate into the plasmamembrane has not been determined, but computer-based motif analysis predicts an intramembraneous (hydrophobic) segment and a myristoylation site for reggie-1, and an intramembraneous (hydrophobic) sequence segment for reggie-2.
That reggie proteins are associated with the plasmamembrane has been determined by light- and electron-microscopic immunostaining experiments. The use of antibodies recognizing specifically either reggie-1 or reggie-2 and quantitative analysis of the resulting immunofluorescent puncta in flattened growth cone membranes enabled us to show that a substantial fraction of reggie-1 and reggie- 2 patches are colocalized. The punctate distribution of the immunofluorescence indicates that each occupies discrete sites of the plasmamembrane and that these sites partially overlap. The punctate pattern is similar to that obtained with anti-caveolin, but for the cells under consideration here, we can rule out that reggie proteins are localized to caveolae (see below).

Bickel et al. (1997) suggested that "flotillin-1 and ESA define a new family of caveola-associated inte-

Table 4 Quantification of Gold Grains

\begin{tabular}{|c|c|c|c|c|c|c|c|c|c|c|}
\hline AB Used & $\begin{array}{l}\text { Labeling } \\
\text { Density }\end{array}$ & \multicolumn{9}{|c|}{ Au Grains per Labeled Site } \\
\hline & Gold grains $/ \mu \mathrm{m}$ & 1 & 2 & 3 & 4 & 5 & 6 & 7 & 8 & 9 \\
\hline (a) $1 \mathrm{st} \rightarrow 2 \mathrm{nd} \mathrm{AB}-\mathrm{Au}_{5}$ & 0.489 & 12 & 6 & 23 & 23 & 12 & 6 & 6 & 6 & $6 \%$ \\
\hline (b) 2 nd $\mathrm{AB}-\mathrm{Au}_{5}$ only & 0.036 & $100 \%$ & & & & & & & & \\
\hline
\end{tabular}

Ratio (a)/(b) = 13.6. Unicryl sections through DRGs neurons [fixation method (c)] were exposed to (a) mAB anti-ESA/reggie-1 (1st) and secondary immunogold-conjugated antibodies $\left(2 \mathrm{nd} \mathrm{AB}-\mathrm{Au}_{5}\right)$. (b) Controls were treated with 2 nd $\mathrm{AB}-\mathrm{Au}_{5}$ only (first column). Gold grains occurring within a distance of $25 \mathrm{~nm}$ from the plasmamembrane inside the cell were counted and set into relation to the length (in micrometers) of the plasmamembrane examined (second column). The frequency with which gold grains occurred at the cell membrane per labeled site is expressed as a percentage (third column). In controls treated with the secondary $\mathrm{AB}-\mathrm{Au}_{5}$ only single gold grains were found per site (frequency $100 \%$ ), whereas labeled sites exhibited between one and nine gold grains (average 4) when the first and secondary $\mathrm{AB}-\mathrm{Au}_{5}$ were applied $(\mathrm{a})$. The ratio of labeling in experimental over control is 13.6. 

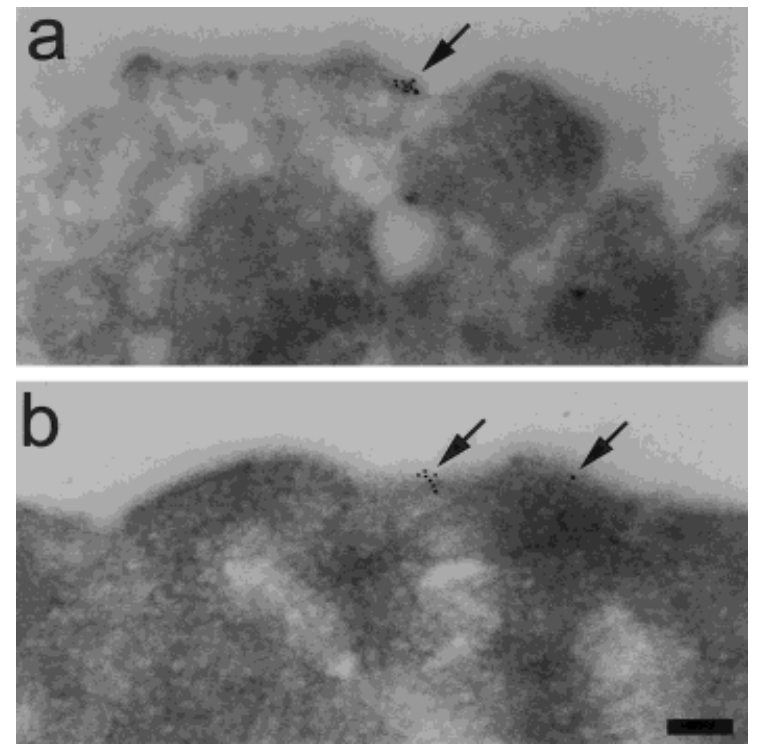

Figure 11 Immunogold detection of reggie-1 in DRG neurons. Small clusters of immunogold as well as occasional single gold particles (arrows) are localized at the plasmamembrane. The cell in (a) was fixed in formaldehyde and picric acid, and the cell in (b) by formaldehyde and glutaraldehyde [methods (d) and (c) in Materials and Methods]. Scale bar $=0.1 \mu \mathrm{m}$.

gral membrane proteins." Flotillin-1 and ESA, the homologs of reggie-2 and -1 , are enriched in a fraction characterized by its nonionic detergent insolubility (Bickel et al., 1997; the current study). This fraction contains caveolin when derived from nonneuronal cells (Lisanti et al., 1994; Kurzchalia et al., 1995) or from the brain (see below). It has been proposed that flotillin-1 may represent a new marker for caveolae or caveolae-like structures in the brain, and that ESA henceforth be known as flotillin-2 (Bickel et al., 1997). This and the controversy over the existence of caveolae and caveolin in neurons and the brain (Ying et al., 1992; Shyng et al., 1994; Olive et al., 1995; Cameron et al., 1997; Bickel et al., 1997) led to the present quantitative ultrastructural analysis. Evaluation of representative sample sizes demonstrates that caveolae are absent from neurons, or at least from RGCs, DRG neurons, and PC-12 cells. These as well as other neurons (hippocampal and cerebellar neurons, unpublished results), however, do express reggie- 1 and -2 .

In DRG neurons and with immunogold labeling, reggie-1 protein is found at the plasmamembrane where no morphologically distinct vesicular structure is recognized. The occurrence of distinct immunogold clusters is consistent with and confirms light-microscopic immunofluorescence data indicating the accumulation of reggie- 1 and -2 protein in patches. Caveolae were claimed to be sensitive to chemical fixation (reviewed in Anderson, 1993; Shyng et al., 1994) and could thus disappear (or form) depending on the pretreatment of cells subjected to ultrastructural analyses. A comparison of cells which have undergone rapid freezing or chemical fixation shows that $\mathrm{OsO}_{4}$ influences the number of caveolae found per square micrometer of membrane in astrocytes, but does not alter their shape significantly. Moreover, as both techniques were applied to neurons relevant to this study, we are confident that no such caveola-like invagina-

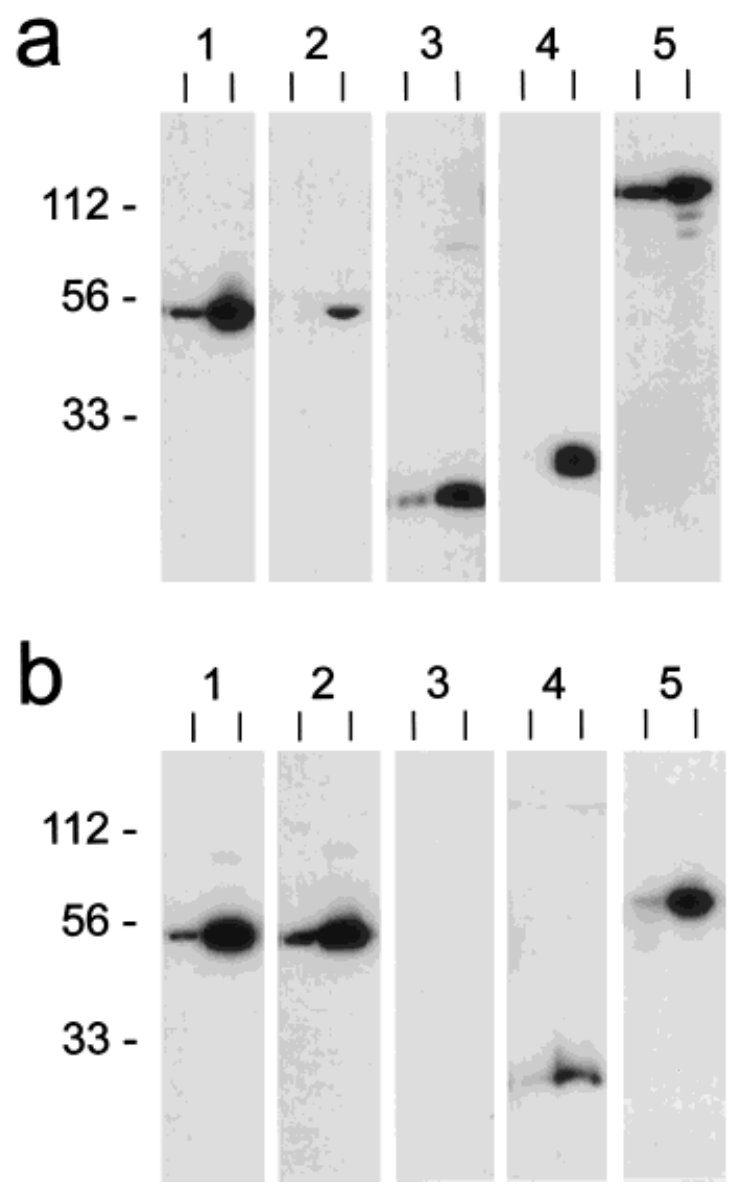

Figure 12 Reggie-1 and reggie-2 are enriched in detergent insoluble membrane fractions. (a) Immunoblots with proteins from the neonatal rat CNS: Triton-X-100 soluble proteins (left lanes); and Triton-X 100 insoluble proteins (right lanes). Blots were exposed to the following antibodies: anti-ESA/reggie-1 (lane 1); anti-reggie-2 (lane 2); anticaveolin (lane 3); anti-Thy-1 (lane 4); anti-F3 (lane 5). Note that all Triton- $X$ insoluble samples exhibit stronger signals than the soluble ones. (b) Immunoblots with proteins from PC-12 cells: Triton-X-100 soluble (left lanes); Triton-X-100 insoluble (right lanes). Blots in lanes 1-4 were exposed to the same antibodies as in (a). In 5, anti-c-src was used instead of anti-F3 (because PC-12 cells are F3 negative). Again, the signals are stronger in the right lanes. Lane 3 shows that PC-12 cells are anti-caveolin negative. The concentration of loaded proteins is the same in all lanes. 
tions exist in DRGs, fish RGCs, or PC-12 cells. This is consistent with the absence of caveolin in immunostaining (DRG neurons and PC-12 cells) and immunoblot experiments (PC-12 cells). On the other hand, immunoblots with rat brain homogenates and anti-caveolin $\mathrm{ABs}$ did reveal the $21-\mathrm{kD}$ caveolin band, which is to be expected considering the finding that astrocytes, oligodendrocytes, and brain endothelial cells (Cameron et al., 1997) express caveolin. Because available antibodies fail to recognize caveolin in fish, immunoblot and immunolabeling experiments could not be performed.

The so-called buoyant fraction in which flotillin-1 and ESA (i.e., reggie-2 and -1) accumulate also contains $s r c$ family kinases, GPI-linked proteins (Anderson, 1993; Brown, 1993; Sargiacomo et al., 1993; Olive et al., 1995), GTP-binding proteins ( $\mathrm{Li}$ et al., 1995), and caveolin (Bickel et al., 1997). It has been proposed that molecules enriched in this fraction can assemble in the plane of the membrane and function as foci for transmembrane signaling (Lisanti et al., 1994), especially when GPI-anchored proteins are activated through binding of the natural ligand or through crosslinking by antibodies (Stefanova et al., 1991; Mayor et al., 1994). Therefore, caveolae and caveolin are thought to be involved in translating the signals from the cell exterior into the cell (Sargiacomo et al., 1993; Lisanti et al., 1994; Li et al., 1995). It has, however, also been proposed that activated GPIlinked proteins assemble in foci outside of caveolae (Schnitzer et al., 1995, 1997; Liu et al., 1997; Harder and Simons, 1997) but are enriched in the same fraction as caveolin. Moreover, signal transduction events upon activation of GPI-anchored proteins have been observed in lymphocytes which lack caveolin and caveolae (Fra et al., 1994). Thus, the enrichment of flotillin-1 and ESA/flotillin-2 (alias reggie-2 and -1) in fractions rich in caveolin (Bickel et al., 1997 and here) demonstrates their preferential accumulation in Triton-X-100-insoluble fractions but does not prove they coexist in the plane of membrane (Fra et al., 1994; Harder and Simon, 1997). In fact, reggie-1 and -2 are enriched in the detergent-insoluble membrane fraction in PC-12 cells which lack caveolin and caveolae.

That caveolae and reggie micropatches represent separate microdomains is suggested by our findings that caveolin and reggie often do not coexist in the same cell. This has been demonstrated for DRG neurons, RGCs, and PC-12 cells. Moreover, our finding that reggie micropatches occur in astrocytes in a pattern different from the arrays of anti-caveolin puncta suggests that caveolin and reggie define micropatches which are separate entities when both are expressed in the same cell. This is supported by the observation that astrocytes lose their punctate anti-caveolin $\mathrm{AB}$ immunofluorescence pattern after exposure to filipin, but preserve the reggie-1 micropatches. This indicates that the distribution of reggie proteins is not visibly altered by the cholesterol-binding agent (Rothberg et al., 1990, 1992). Whether reggie micropatches are associated with glycolipid-rich membrane domains remains to be clarified.

Signal transduction events after activation and clustering of GPI-linked cell-surface proteins have also been proposed to occur in neuroblastoma cells, but whether they possess caveolae is disputed (Ying et al., 1992; Shyng et al., 1994; Hermey et al., 1995; Gorodinsky and Harris, 1995). In fact, neuroblastoma cells are the only neuronal cells for which we found direct (and controversial) documentation in the literature of the existence of caveolae.

Consistent with the notion that activated GPIlinked proteins assemble in microclusters (Mayor et al., 1994) is our finding that the CAMs F3 and Thy-1 cluster in the plane of the membrane upon antibody crosslinking. These clusters are colocalized with reggie micropatches to an extent that was observed in colocalization studies for Thy-1 and other GPI-linked proteins and caveolin (Mayor et al., 1994) or caveolae (Ying et al., 1992) in nonneuronal cells. In DRG neurons, therefore, GPI-linked protein clusters form, much as in lymphocytes (Fra et al., 1994), without caveolae and caveolin. Since reggie proteins are localized to the cell membrane and may have intramembrane domains, it is possible that they participate in the establishment of communication between the surface and the cytoplasm, as was suggested for caveolin (Lisanti at al., 1994). Moreover, reggie-1 and -2 are thought to possess multiple phosphorylation sites (as does caveolin) (Glenney and Soppet, 1989). Also, the detergent-insoluble membrane fraction of PC-12 cells where reggie-1 and -2 and the GPI-linked CAMs are enriched and from which caveolin is absent does contain c-src [Fig. 12(b)]. However, it is not presently known whether reggie proteins interact with lipidlinked kinases, such as those of the $\operatorname{src}$ family. As the CAMs F3 and Thy-1 preferentially cluster with reggie micropatches in DRG neurons, however, it is conceivable that reggie- 1 and -2 define sites for the preferential assembly of these CAMs.

The function of reggie proteins may be better understood by exploring their expression in neurons and in the brain during development and neuronal differentiation. In the fish retina, which contains RGC axons connected with the target as well as newly formed growing axons (Stuermer et al., 1992), only the new RGCs and RGC axons express reggie (Schulte et al., 1997). This supports the view that reggie proteins accompany axon growth. It is of interest that all 
neuronal cell types analyzed in detail exhibit reggie proteins on their axons, growth cones, and filopodia. These distal tips of axons actively explore their environment. Signals received by the growth cone determine whether an axon elongates, turns, or ceases to grow. RGCs which extend or regenerate their axons up-regulate synthesis of reggie mRNAs, and it is therefore quite likely that reggie proteins play a role in axon growth, and regeneration. Up-regulation occurs in goldfish (Schulte et al., 1997) and even in rats, where the number of axon-regenerating RGCs is small and where transplantation of a peripheral nerve graft is required for in vivo axon regrowth (Aguayo et al., 1991). Regeneration of axons in goldfish is accompanied by the reexpression of proteins which were present during axon growth in the embryo (Stuermer et al., 1992). This includes GPI-linked CAMs (Lang et al., 1998; Lang and Stuermer, unpublished results). GPI-linked CAMs including F3 and Thy-1 have been demonstrated to participate in axon growth and navigation (Gennarini et al., 1989; Brümmendorf et al., 1993; Mahanthappa and Patterson, 1992; Dreyer et al., 1995). It remains to be seen whether GPI-linked CAMs activated by their natural ligands will cocluster with reggie micropatches and whether the proposed signal transduction events are elicited (Olive et al., 1995; Lisanti et al., 1995) during axon growth and regeneration.

The authors thank Dr. G. Gennarini for providing the antibody against F3, and Dr. F. Rathjen for the L1 antibody. They authors gratefully acknowledge the help of C. Braun and S. Kolassa with EM preparations, and Dr. J. Hentschel and H. Rheinfrank for data analysis. Jörn Schröder and Frank Dehner helped with the in situ hybridization experiments and Northern blot analyses. Christian Leppert participated in the initial reggie immunostaining experiments, and Katja Eichert helped screen reggie-2 monoclonal antibodies. This work was supported by grants of the Deutsche Forschungsgemeinschaft (DFG) to HP and CAOS, by the Bundesministerium für Bildung und Forschung (BMBF) and Fonds der Chemischen Industrie (FCI) to CAOS.

\section{REFERENCES}

Aguayo, A. J., Rasminsky, Bray, M. G. M., Carbonetto, S., McKerracher, L., Villegas-Perez, M. P., VidalSAnZ, M., and CARTER, D. A. (1991). Degenerative and regenerative responses of injured neurons in the central nervous system of adult mammals. Philos. Trans. R. Soc. London Biol. 331:337-343.

Amur-Umarjee, S., Phan, T., and Campagnoni, A. T. (1993). Myelin basic protein mRNA translocation in oligodendrocytes is inhibited by astrocytes in vitro. J. Neurosci. Res. 36:99-110.
Anderson, R. G. W. (1993). Plasmalemmal caveolae and GPI-anchored membrane proteins. Curr. Opin. Cell. Biol. 5:647-652.

Bickel, P. E., Scherer, P. E., Schnitzer, J. E., Oh, P., Lisanti, M. P., and Lodish, H. F. (1997). Flotillin and epidermal surface antigen define a new family of caveolae-associated integral membrane proteins. J. Biol. Chem. 272: 19793-19802.

Bottenstein, J. E., and SAto, G. H. (1979). Growth of a rat neuroblastoma cell line in serum-free supplemented medium. Proc. Natl. Acad. Sci. USA, 76:514-517.

Breitschopf, H., Suchanek, G., Gould, R. M., Colman, D. R., and Lassmann, H. (1992). In situ hybridization with digoxigenin-labelled probes: sensitive and reliable detection method applied to myelinating rat brain. Acta Neuropathol. 84:581-587.

Brown, D. (1993). The tyrosine kinase connection: how GPI-anchored proteins activate T-cells. Curr. Opin. Immunol. 5:349-354.

Brümmendorf, T., Hubert, M., Treubert, U., Leuschner, R., TARnok, A., and Rathjen, F. G. (1993). The axonal recognition protein $\mathrm{F} 11$ is a multifunctional protein: specific domains mediate interactions with $\mathrm{Ng}$-CAM and restriction. Neuron 10:711-727.

Cameron, P. L., Ruffin, J. W., Bollag, R., Rasmussen, H., and CAMERon, R. S. (1997). Identification of caveolin and caveolin-related proteins in the brain. J. Neurosci. 15: 9520-9535.

Chang, W.-J., Ying, Y.-S., Rothberg, K. G., Hooper, N. M., Turner, A. J., Gambliel, H. A., DeGunzburg, J., Mumby, S. M., Gilman, A. G., and Anderson, R. G. W. (1994). Purification and characterization of smooth muscle cell caveolae. J. Cell Biol. 126:127-138.

Dreyer, E. B., Leifer, D., Heng, J. E., McConnel, J. E., Gorla, M., Levin, L. A., Barnstable, C. J., and Lipton, S. A. (1995). An astrocytic binding site for neuronal Thy-1 and its effect on neurite outgrowth. Proc. Natl. Acad. Sci. USA 92:11195-11199.

Fra, A. M., Williamson, E., Simons, K., and Parton, R. G. (1994). Detergent-insoluble glycolipid microdomains in lymphocytes in the absence of caveolae. J. Biol. Chem. 269:30745-30748.

Galbiati, F., Volonte, D., Goltz, J. S., Steele, Z., Sen, J., Jurcsak, J., Tein, D., Stevens, L., and Lisanti, M. P. (1998). Identification, sequence and developmental expression of invertebrate flotillins from Drosophila melanogaster. Gene 210:229-237.

Gennarini, G., Cibelli, C., Rougon, G., Mattei, M.-G., and Goridis, C. (1989). The mouse neuronal cell surface protein F3: a phosphatidylinositol-anchored member of the immunoglobulin superfamily related to chicken contactin. J. Cell Biol. 109:775-788.

Glenney, J. R., and Soppet, D. (1989). Sequence and expression of caveolin, a protein component of caveolae plasma membrane domains phosphorylated on tyrosine in Rous sarcoma virus-transformed fibroblasts. Proc. Natl. Acad. Sci. USA 89:10517-10521.

Gorodinsky, A., and Harris, D. A. (1995). Glycolipidanchored proteins in neuroblastoma cells form detergent- 
resistant complexes without caveolin. J. Cell Biol. 129: $619-627$.

Harder, T., and Simons, K. (1997). Caveolae, DIGs, and the dynamics of sphingolipid-cholesterol microdomains. Curr. Opin. Cell Biol. 9:534-542.

Henke, R. C., Hancox, K. A., and Jefrrey, P. L. (1996). Characterization of two distinct populations of detergent resistant membrane complexes isolated from chick brain tissues. J. Neurosci. Res. 45:617-630.

Hermey, J. H., Doyle, D., Brown, V., and Rogers, M. S. (1995). The cellular isoform of the prion protein, PrPc, is associated with caveolae in mouse neuroblastoma (N2a) cells. Biochem. Biophys. Res. Commun. 210:753-759.

Jung, M., Petrausch, B., and Stuermer, C. A. O. (1997). Axon-regenerating retinal ganglion cells in adult rats synthesize the cell adhesion molecule L1 but not TAG-1 or SC-1. Mol. Cell. Neurosc. 9:116-131.

Knoll, G., Braun, C., and Plattner, H. (1991). Quenched flow analysis of exocytosis in paramecium cells: time course, changes in membrane structure and calcium requirements revealed after rapid mixing and rapid freezing of intact cells. J. Cell Biol. 113:1295-1304.

Kurzchalia, T. V., Hartmann, E., and Dupree, P. (1995). Guilt by insolubility-does a protein's detergent-insolubility reflect a caveolar location? Trends Cell Biol. 5:187-189.

Lang, D. M., Hille, M. G., Schwab, M. E., and Stuermer, C. A. O. (1996). Modulation of the inhibitory substrate properties of oligodendrocytes by platelet-derived growth factor. J. Neurosci. 16:5741-5748.

Lang, D. M., and Stuermer, C. A. O. (1996). Adaptive plasticity of Xenopus glial cells in vitro and in vivo. Glia 18:92-106.

Lang, D. M., Leppert, C. A., Wiechers, M., and Stuermer, C. A. O. (1998). Mab M 802 recognizes a $48 \mathrm{kDa}$ GPI-anchored cell surface protein involved in axonal guidance. Eur. J. Neurosci. 10(Suppl.): 274.

Li, S., Окамoto, T., Chun, M., Sargiacomo, M., Casanova, J. E., Hansen, S. H., Nishimoto, I., and LisANTi, M. P. (1995). Evidence for a regulated interaction between heterotrimeric $\mathrm{G}$ proteins and caveolin. J. Biol. Chem. 270:15693-15701.

Lisanti, M. P., Scherer, P. E., Tang, Z., Kübler, E., Koleske, A. J., and Sargiacomo, M. (1995). Caveolae and human disease: functional roles in transcytosis, potocytosis, signalling and cell polarity. Dev. Biol. 6:47-58.

Lisanti, M. P., Scherer, P. E., Tang, Z. L., and SargiaCOMO, M. (1994). Caveolae, caveolin and caveolin-rich membrane domains: a signalling hypothesis. Trends Cell Biol. 4:231-235.

Liu, J., OH, P., Horner, T., Rogers, R. A., and Schnitzer, J. E. (1997). Organized endothelial cell surface signal transduction in caveolae distinct from glycosylphosphatidylinositol-anchored protein microdomains. J. Biol. Chem. 11:7211-7222.

Mahanthappa, N. K., and Patterson, P. (1992). Thy-1 involvement in neurite outgrowth: perturbation by antibodies, phospholipase C, and mutation. Dev. Biol. 150: 47-59.

Mains, R. E., and Patterson, P. H. (1973). Primary cultures of dissociated sympathetic neurons. 1. Establishment of long-term growth in culture and studies of differentiated properties. J. Cell Biol. 59:329-345.

Mayor, S., Rothberg, K. G., and Maxfield, F. R. (1994). Sequestration of GPI-anchored proteins in caveolae triggered by cross-linking. Science 264:1948-1951.

McCarthy, K. D., and De Vellis, J. (1980). Preparation of separate astrocyte and oligodendrocyte cultures from rat cerebral tissue. J. Cell Biol. 85:890-902.

Monier, S., Parton, R. G., Vogel, F., Henske, A., and Kurzchalia, T. V. (1995). VIP-21-caveolin, a membrane constituent of the caveolar coat forms high molecular mass oligomers in vivo and in vitro. Mol. Biol. Cell. 6:911-927.

Olive, S., Dubois, C., Schachner, M., and Rougon, G. (1995). The F3 neuronal glycosylphosphatidylinositollinked molecule is localized to glycolipid-enriched membrane subdomains and interacts with L1 and Fyn kinase in cerebellum. J. Neurochem. 65:2307-2317.

Parton, R. G. (1996). Caveolae and caveolins. Curr. Opin. Cell Biol. 8:542-548.

Plattner, H., Artalejo, A. R., and Neher, E. (1997). Ultrastructural organization of bovine chromaffin cell cortex-analysis by cryofixation and morphometry of aspects pertinent to exocytosis. J. Cell Biol. 139:17091717.

PlattNer, H., and Zingsheim, H. P. (1983). Electron microscopic methods in cellular and molecular biology. Subcell. Biochem. 9:1-236.

Plattner, H., and Bachmann, L. (1982). Cryofixation: a tool in biological ultrastructural research. Int. Rev. Cytol. 79:237-304.

Paschke, K. A., Lottspeich, F., and Stuermer, C. A. O. (1992). Neurolin, a cell surface glycoprotein on growing retinal axons in the goldfish visual system is re-expressed during retinal axonal regeneration. J. Cell Biol. 117:864875.

Pscheid, P., Schudt, C., and Plattner, H. (1981). Cryofixation of monolayer cell cultures for freeze-fracturing without chemical pre-treatments. J. Microsc. (Oxford) 121:149-167.

Rothberg, K., Heuser, J. E., Donzell, W. C., Ying, Y.-S., Glenney, J. R., and Anderson, R. G. W. (1992). Caveolin, a protein component of caveolae coats. Cell 68:673682.

Rothberg, K. G., Ying, Y. S., Kamen, B. A., and AnderSON, R. G. (1990). Cholesterol controls the clustering of the glycophospholipid-anchored membrane receptor for 5-methyltetrahydrofolate. J. Cell Biol. 111:2931-2938.

Sambrook, J., Fritsch, E. F., and Maniatis, T. (1989). Molecular Cloning: A Laboratory Manual, 2nd ed. Cold Spring Harbor Laboratory Press, Cold Spring Harbor, New York.

SAnger, F., Nicklen, S., and Coulson, A. R. (1977). DNA sequencing with chain-terminating inhibitors. Proc. Natl. Acad. Sci. USA 74:5463-5467.

Sargiacomo, M., Sudol, M., Tang, Z. L., and Lisanti, M. P. (1993). Signal transducing molecules and glycosylphosphatidylinositol-linked proteins form a caveolin-rich 
insoluble complex in MDCK cells. J. Cell Biol. 122:789807.

Schnitzer, J. E., McIntosh, D. P., Dvorak, A. M., Liu, J., and Он, Р. (1995). Separation of caveolae from associated microdomains of GPI-anchored proteins. Science 269:1435-1439.

Schnitzer, J. E., OH, P., and McIntosh, D. P. (1997). Role of GTP hydrolysis in fission of caveolae directly from plasma membranes. Science 274:239-242.

Schroeder, W., Stewart-GaletKa, S., Mandavilli, S., Parry, D. A., Goldsmith, D., and Duvic, M. L. (1994). Cloning and characterization of a novel epidermal cell surface antigen (ESA). J. Biol. Chem. 269:19983-19991.

Schulte, T., Paschke, K., Laessing, U., LotTsPeich, F., and Stuermer, C. A. O. (1997). Reggie-1 and reggie-2, two cell surface proteins expressed by retinal ganglion cells during axon regeneration. Development 124:577-587.

Shyng, S.-L., Heuser, J. E., and Harris, D. A. (1994). A glycolipid-anchored prion protein is endocytosed via clathrin-coated pits. J. Cell Biol. 125:1239-1250.

Stefanova, I., Horejsi, V., Ansotegui, I. J., Knapp, W., and
Stockinger, H. (1991). GPI-anchored cell-surface molecules complexed to protein tyrosine kinases. Science 254: 1016-1017.

Stuermer, C. A. O., Bastmeyer, M., Bähr, M., Strobel, G., and PASCHKE, K. (1992). Trying to understand axonal regeneration in the CNS of fish. J. Neurobiol. 23:537-559.

Vielmetter, J., Lottspeich, F., and Stuermer, C. A. O. (1991). The monoclonal antibody E587 recognizes growing (new and regenerating) retinal axons in the goldfish retinotectal pathway. J. Neurosci. 11:3581-3593.

Westerfield, M. (1994). The Zebrafish Book: A Guide for the Laboratory Use of Zebrafish (Brachydanio rerio). University of Oregon Press, Eugene, OR.

Wilkinson, D. G. (1992). In Situ Hybridization: A Practical Approach. IRL Press at Oxford University Press, Oxford. Ying, Y.-S., Anderson, R. G. W., and RothberG, K. G. (1992). Each caveola contains multiple glycosyl-phosphatidylinositol-anchored membrane proteins. In: Cold Spring Harbor Symposia on Quantitative Biology, Vol. LVII, Cold Spring Harbor Laboratory Press, Cold Spring Harbor, New York, pp. 593-604. 